\title{
DETERMINAÇÃO ESPECTROFOTOMÉTRICA DE URÂNIO EM ROCHAS E ÁGUAS NATURAIS EMPREGANDO SISTEMA DE INJECCÃO EM FLUXO
}

\author{
NELSON NEPOMUCENO
}

Orientador: DR. HENRIQUE BERGAMIN FILHO

Dissertação apresentada à Escola Superior de Agricultura "Luiz de Queiroz", da Universidade de São Paulo, para obtenção do Título de Mestre em Agronomia - Área de Concentração: "Energia Nuclear na Agricultura".

P I R A C I C A B A

Estado de São Paulo - Brasil

Dezembro - 1982 


\footnotetext{
A minha esposa, Gräcia Maria, e a meus fithos, Femanda, Netson e Eernanato, $D E D I C O$.
}

A Elias A.G. Zagatto, Uiratan Pereira Jardim e Jefferson Mortatti, pela dedicação constante e amiga, $O F E R E S O$. 


\section{AGRADECIMENTOS}

- Ao Prof. Dr. Henrique Bergamin Filho, pela oxientação;

- Ao MS. Francísco Josê krug, Chefe da Divisão de Ciências Básicas do Cen tro de Energia Nuclear na Agricultura (CENA), pela inestimável ajuda re cebi.da;

- Aos professores Dr. Elias Ayres Guidetti Zagatto e Dr. Antonio Otávio Ja cintho pelo apoio irrestrito em todas as etapas do presente trabalho;

- Aos colegas Boaventura Freire dos Reis, Maria Fernanda R. Giné, Virgỉlio Franco do Nascimento Filho; Luiz Carlos Ruiz Pessenda, Jefferson Mortat ti, Elisabete De Nadai Fernandes e Nunzio Di Gregorio pelas sugestões e discussões durante o desenvolvimento experimental;

- Ao Centro de Energia Nuclear na Agricultura (CENA), pelas facilidades o ferecidas para a realização deste trabalho;

- Aos têcnicos de laboratório Iolanda Aparecida Rufini, Nelson Della Va1le Filho, Ubiratan Pereira Jardim e Waldemix Aparecido Fernandes de Bar ros, pela constante colaboração e amizade;

- A Sra. Neusa Maria Costa Pereîra, da Divisão de Ensino e Extensão do CENA, pelo encaminhamento e orientação;

- A Srta. Alzixa Ferraz pela datilografia dos originais deste trabalho e pela paciência e amizade sempre demonstradas;

- Ao colega Oscar Bahia Filho, pela confeç̧ão dos desenhos;

- A todos os funcionários do CENA, pela convivência amiga e prestimesa e a todas as pessoas que de uma ou de outra forma contribuiram para a exe cução deste trabalho. 
SUMMARY ......................... . . . . vii

1. INTRODUÇÃO . . . . . . . . . . . . . . . . . . . . . . . . 01

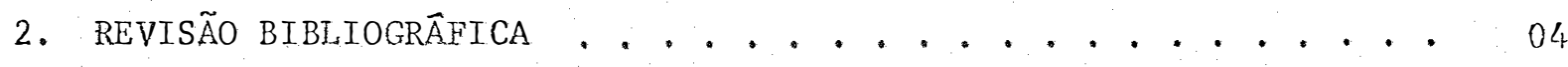

2.1. Determinação de urânio ........................... 04

2.2. Automatização de anâlises . . . . . . . . . . . . . 09

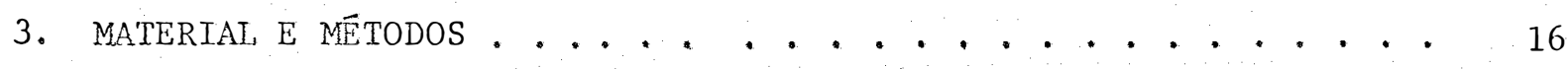

3.1. Instrumentos e acessórios .......................... 16

3.2. Reagentes, padrões e amostras . . . . . . . . . . 17

3.2.1. Reagentes.......................... 17

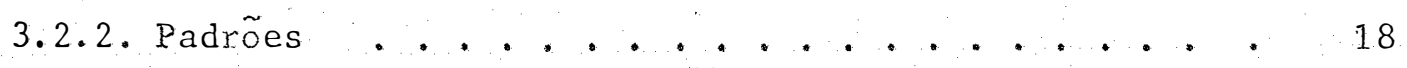

3.2.3. Amostras ............................ 19

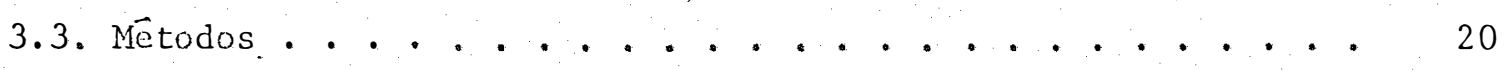

3.3.1. Considerações gerais . . . . . . . . . . 20

3.3.2. Dibenzoilmetano e sua reação com o ion uranila . . 21

3.3.3. Mẻtodo automático de anâlise por injeção em fluxo . . 23

3.3.4. Projeto do sistema de injeção em fluxo para análise

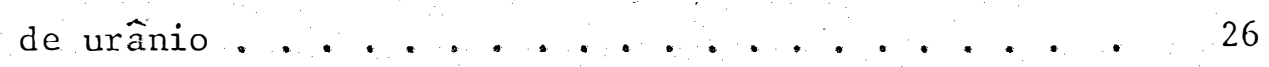

3.3.5. Definição do comprimento de onda....... 28

3.3.6. Efeito do volume injetado de amostras . . . . . 28

3.3.7. Influência da concentração de dibenzoilmetano . . . 29

3.3.8. Efeito da acidez.................. 29

3.3.9. Efeito do comprimento da bobina de mistura . . . . 30

3.3.10.Efeito dos íons interferentes . . . . . . . : 30 
.ii.

Pāgina

3.3.11. Características analíticas .......... . . 34

3.3 .11 .1 . Exatidão .............. 34

3.3 .11 .2 . Precisão ............ 34

3.3.11.3. Velocidade analítica e consumo de reagentes. 36

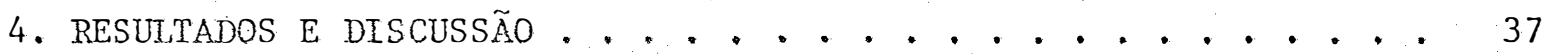

4.1. Definição do comprimento de onda .......... 37

4.2. Efeito do volume injetado de amostra......... 39

4.3. Influência de concentração de dibenzoilmetano ...... 41

4.4. Efeito da acidez da amostra ............ 43

4.5. Efeito do comprinento de bobina de mistura . . . . . . 43

4.6. Efeito dos ions interferentes ........... 45

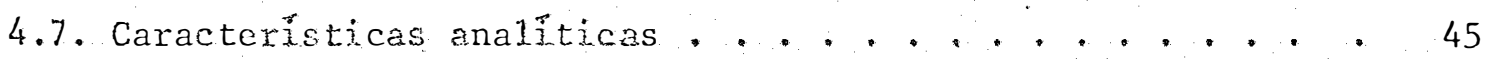

4.7.1. Exatidão . . . . . . . . . 45

4.7 .2 . Precisão . . . . . . . . . . 49

4.7.3. Velocidade analitica e consiuno de reagentes,... 50

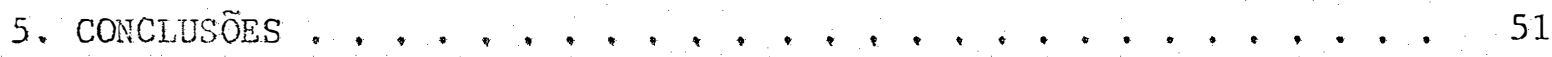

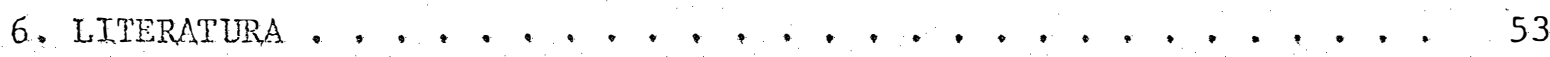


1 Tolerância aos diversos ions. Concentrações mäximas pex

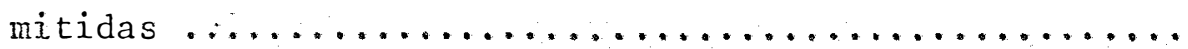

2 Padrões de urânio, contendo os íns interferentes .... 33

3 Interferência, dos diversos íons, na determinação do urânio. "Performance" do EDTA como mascarante ........ 46

4 Comparação dos resultados obtidos, na determinação de urânio nas amostras certificadas da AIEA ........... 


\section{LISTA DE FIGURAS}

.$v$.

Figura

Pāgina

1 Diagrama de blocos de um sistema de anālise por injeção ....... 23

2 Injetor de amostras com duas Secções de Comutação ........... 25

3 Diagrana de fluxo do sistema projetado para anālise de urânio ... 27

4 Diagrama de fluxos para estudo dos íns interferentes ........ 32

5 Diagrama de fluxos utilizado para a determinação de urânio em ro-

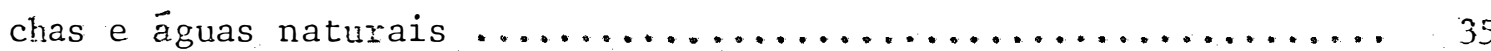

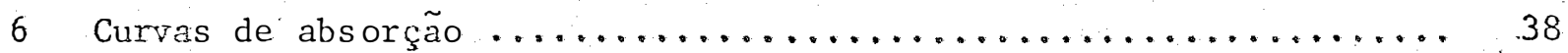

7 Efeito do volume de amostras injetado no sistema de fluxo, propos

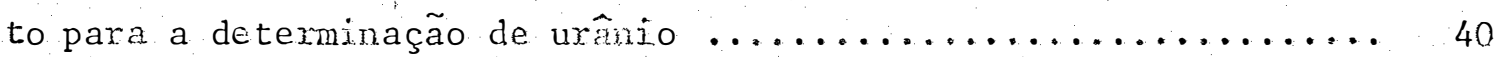

8 Efeito de concentração de dibenzoilmetano $\ldots \ldots \ldots \ldots \ldots \ldots \ldots \ldots \ldots$

9. Efeito do comprimento da bobina de mistura $\ldots \ldots \ldots \ldots \ldots \ldots \ldots$

10. Resultados de determinação de urânio em àguas naturais e minérios

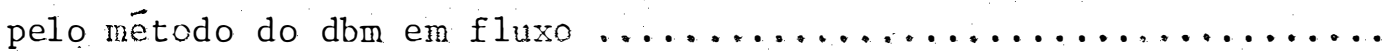


.vi.

Determinação espectrofotométrica de urânio em rochas e ãguas naturais em pregando sistema de injeção em fluxo.

NeZson Nepomuceno

Orientador: Henrique Bergamin Fitho

RESUMO

Desenvolyeu-sẹ um método para a determinação de urânio, em rochas e águas naturais, através da reação com dibenzoilmetano, em fase ü nica, empregandorse um sjistema analîtico de injeção em fluxo.

Foram estudados inicialmente, os fatores que incidiam dire tamente sobre a sensibilidade do método proposto, como as concentrações dos reagenies, volumes injetados de amostras, interfe rentes e melhores condições de acidez para otimização da determinação.

Com o sistema de fluxo estabelecido, conseguiu-se uma velo cịdade analítica de 80 determinações por hora, na falxa de 0,25 a $10 \mathrm{ppm}$ de U. Foi conseguida uma recuperação de $99,93 \%$ em análises de amostras reais. Precisão de $97,92 \%$, para medidas de amostras com 4,0 ppm de $U$, pode ser conseguida.

O sistema empregado e detalhes de consumo de reagentes, mas caramento, utilização de material certificado como referência, necessidade de separação prévia para amostxas contendo ferro, foram discutidos. 
.vii.

Spectrofotometric determination of uranium in rocks and natural waters by flow injection analysis.

\section{Nelson Nepomuceno}

Adviser: Henrique Bergamin Fitho

SUMMARY

A flow injection procedure for the determination of uranium in rocks and natural waters using reaction with dibenzoilmethane in single phase has been developed.

Main sensitivity factors, such as reagent consentrations, sample injected volume, interfering ions and acidity conditions were inves tigated.

The proposed system is characterized by a sampling rate of 80 measurements per hour, in the $0.25-10 \mathrm{ppm} U$ range. Recoyexy of 9.9.93\% in the analysis of real sample was assessed, typical precision of $97.92 \%$ for the measurement of a 4.0 ppm U sampie was calculated after ten measurements .

Systems design and details of reagent consuption, masking, utilization of certified reference materials needed for iron separation prior to sample injection etc, are discussed. 


\section{INTRODUÇAO}

Grande parte das pesquisas sobre energia atômica foi dirigida para as reações nucleares do urânio. Por isso este elemento tornouse um dos mais pesquisados e extraídos. A fissão nuclear de 0,500 kg de urânio produz energia térmica equivalente a 5.900 barris de petróleo (SKIN NER, 1970). Deste modo, mesmo reservas moderadas desse elemento, consti tuem um inenso recurso energético,

O urânio ê um elemento geoquimicamente escasso, mas pelo fato de ser usado como combustivel de alto poder energetico, sua pros peç̧ão e extração tornaram-se comercialmente atraentes. Devido à sua gran de importância estratégica no mundo atual e o crescente consumo, as reser vas conhecidas de seus minérios esgotar-se-̃̃o em pouco tempo. Torna-se, pois, vital a tentativa de se localizar novas jazidas.

A distribuição do urânio na crosta terrestre é função dos nümeros de oxidação mais comuns que pode assumir: to 4 e t6. Em rochas igneas silicatadas, pegmatitas e veios hidrotermäis de origem magmätica, o urânio é encontrado com uraninita, apresentando nümero de oxidação +4. Oxi da facilmente para $U^{+6}$ em condições superfixiais, após combinação com oxi gênio, formando o İon complexo uranila $\left(\mathrm{UO}_{2}\right)^{+2}$ que posteriormente origina outros compostos, como carbonato de uranila, bastante solüvel, o que 
facilita a movimentação do elemento em ăguas superficiais. Em presença de matéria orgânica, agente redutor, yolta para o estado de menor oxidação, + 4, menos solúvel, podendo originar compostos orgânicos, ricos em urânio, sedimentos. Em outros casos, pode substituir outros elementos em determinados minerais. Isto é comum na apatita, $\mathrm{Ca}_{5}\left(\mathrm{PO}_{4}\right)_{3}(\mathrm{OH}, \mathrm{F})$, que apresenta $U^{+} 4$ substituindo àtomos de câlcio (SKTNNER, 1970). Assim, pela anālise de āguas e solos, parece ser possível a localização do minério.

Muitos métodos foram desenvolvidos, nos ūitimos trinta anos, para determinação do elemento urânio. Destacaram-se os métodos espectrofotométricos, espectrogrä́ficos, fluorimétricos, polarogrä́ficos, anālise por ativação com neutrons epitérmicos, anälise por contagem de neutrons retardados de fissão, entre outros. Entretanto, os métodos espectrofotométricos foram os mais explorados, devido:

a) grande nümero de reagentes orgânicos formarem complexos coloxidos de alta absortividade molar com urânị, particularmente na forma de. Ion uranila;

b) serem mêtodos de determinação que evoluindo em sistemas líquidos, facilita a anālise de äguas naturais e soluções;

c) requererem aparelhos mais comuns em laboratórios de Química Analítica, como colorímetros e espectrofotômetros.

A Universidade Técnica da Dinamarca e o Centro de Energia Nuclear ma Agricultura vem desenvolvendo, a partir de 1975, métodos de anā lise baseados na injeção das amostras em fluxo, "FIA" do inglês "Flow Injection Analysis" (RUZICKA e HANSEN, 1975). Um grande nümero de trabalhos foram publicados nesses $\vec{u} 1$ timos sete anos, em diversos países, demonstrando todos que essa nova metodologia tem gerado mētodos analiticos de alta precisão, 
sensibilidade, exatidão, baixo custo e alta velocidade de análise. Desta maneira, desenvolveu-se un método espectrofotométrico, para análise de urânio em rochas, minérios e āguas naturais através do sis tema FIA. 


\section{REVISÃO DE LITERATURA}

A presente revisão foi dividida em duas partes distintas, as quais enfocam mêtodos de determinação de urânio e automatização de anālises.

2.1. Determinação de urānio

YOE et alii (1953) investigaram a reação do dibenzoilmetano (dbn)com urânio (VI) para o desenvolvimento de um método colorimétrico para sua determinação. Estabeleceram que o complexo formado instantaneamen te, apresentava máxima absorbância a $395 \mathrm{~nm}$, e que a faixa ideal de pH encontrava-se entre 6,5 e 8,5. O método seguia a lei de Beer apresentando una sensibilidade de 0,05 ppin de urânio. Estabeleceram a tolerância dos complexos coloridos formados com diversos íons bem como, a separação do urânio, dos interferentes, com èter."

ADANS e MAECK (1954) desenvolveram um sistema de operação e manipulação para anâlise de espécies geológicas contendo menos de 10 ppm de urânio. Métodos de decomposição da amostra e procedimentos de extração por solventes visando separação do urânio de interferentes foram investigados. O método fluorimétrico foi estudado e comparado com o mê- 
todo colorimétrico de YOE (1953). Em geral, amostras apresentando menos que $10 \mathrm{ppm}$ de urânio eram analisadas fluorimetricamente e mais que 10ppm colorimetricamente.

GUEST e ZIMMERMAN (1955) descreveram o método para de terminação de urânio em materiais com alta concentração. o urânio era separado dos interferentes por meio de extração com acetato de etila, usando nitrato de alumínio como agente salino. Após o urânio ter sido separado de acetato de etila, a determinação colorimétrica se fez pelo mêtodo do hidróxido de sódio-peróxido de hidrogênio.

BLABQUET (1957) descreveu o método de dosagem colorimētrica de urânio com dibenzoilmetano. o complexo era formado em meio aquo so contendo piridina, em presença de EDTA e ācido tartárico. A absorbân cia era medida a $415 \mathrm{~nm}$. O método envolveu somente uma filtração, sendo usado na presença de värias impurezas, tais como, W,V,Ce,Th,F e P. O mé todo descrito tem sido aplicado com resultados satisfatórios na análise de pechblenda, anturcita, torianita, columbita, urano-torianita, tanta lita e carnotita, contendo de 0,05 a $25 \%$ de urânio. Uma sensibilidade de $0,005 \%$ foi reportada.

TACHER e BARKER (1957) estudaram a determinação fluorí mêtrica de urânio e desenvolveram um procedimento aplicável a análises de äguas.

FRANCOIS (1958) separou o ion uranila dos interferentes por extração com solventes a partir de solução de nitrato de alumínio, usando fosfato de tributila em iso-octano. A cor era desenvolvida pela introdução de solução de dibenzoilmetano em piridina, na alíquota de extra 
to, em soluçāo de āgua acetona. A absorbância do complexo resultante, ura nil-dbm, era medida a $410 \mathrm{~nm}$. Cátions comuns, excetuando Th, em concentra ção superior a dez vezes a do ion uranila, não interferiam. A velocidade de anālise era comparāvel ao processo fluorimétrico.

HORTON e WHITE (1958) descreveram um método rápido e simples para determinação de urânio em soluções aquosas. o urânio (VI) era extraído por solução 0,1 M de óxido de tri-n-octil fosfina em ciclohexano, a partir de solução de ácido nítrico. A cor amarela era formada em aliquo ta de extrato oxgânico pela adição de dibenzoilmetano e piridina em à1cool etílico. O efeito de interferentes foi reduzido por medida de absorbância a $416 \mathrm{~nm}$. A faixa de determinação do método foi de 20 a 3000 . ppm de urânio na solução original e o desvio padrão relativo ao redor de $2 \%$.

CHENG (1958) relatou um reativo novo, sensível e seletivo para urânio. Esse reativo, 1-(2-piridilazo)-2-naftol (PAN), reagia com mui. tos metais polivalentes, formando complexos intensamente coloridos. Entre tanto, na presença de fortes agentes complexantes, como EDTA e cianeto, reagia somente com urânio,formando em solução amoniacal um precipitado vex melho escuro finamente dividido. O complexo podiaser extraído com dicloro benzeno e após centrifugação, a absorbância era lida a $570 \mathrm{~mm}$. A cor

era estável e a lei de Beer era obedecida numa faixa ae 0,1 a $5 \cdot 10^{-4}$ mi Iimoles de urânio en $10 \mathrm{~m} \ell$ de solvente. A absortividade molar do complexo formado era 2,3 $\cdot 10^{4}$. Baixas concentrações de urânio puderam ser determi nados na presença de muitos metais, sem separação prévia.

MAECK et alii (1959) descreveram dois métodos espectrofotomêtricos para urânio: para niveis em $\mathrm{mg} / \mathrm{m} 1 \ldots$ o urânio era separado 
como trinitrato de tetrapropilamônio de uranila e a absorbância era medi da, apōs separação da fase orgânica, a $425 \mathrm{~nm}$; para níveis em $\mu \mathrm{g} / \mathrm{ml}(\mathrm{ppm})$ adicionando dibenzoilmetano em àlcool etîlico-piridina, separando a fase orgânica e lendo a absorbância do quelato a $415 \mathrm{~nm}$. 0 limite de deteçãa para método era de 0,8 ppm, quando se usava o dibenzoilmetano.

POLIARD et alii (1959) investigaram o reativo 4-(2-piridi lazo) - resorcinol (PAR), altamente sensível, solúvel em água, para determinação colorimétrica de cobalto, chumbo e urânio. Na determinação quantitativa do urânio, a solução levemente alcalina do reativo(500 $\mathrm{kg} / \mathrm{m} \ell)$ adicionada às amostras, tamponizadas a $\mathrm{pH}$ 8.0, produzia imediatamente una cor vermelha. As absorbâncias dessas soluções foram medidas a $530 \mathrm{~mm}$ a a sensibilidade era de 0,160 unidades de absorbância por $\mu g U / m \ell$ na faixa de $0,0-6,0 \mu \mathrm{gU} / \mathrm{m} \ell$.

SANDELI (1959) descreveu o uso do reativo dibenzoilmetano na determinação de urânio a pH 6,5 - 8,5 em meio hidroalcoólico contendo piridina. Apresentava como principal vantagem, sua sensibilidade, e como desvantagem, interferência de ferro, cobre, vanādio e molibdênio.

SEIN et alii (1959). desenvolveram um método de separação por troca iônica. O urânio, complexado com dibenzoilmetano em álcool 80\%, $\mathrm{v} / \mathrm{v}$, era determinado colorimetricamente a $400 \mathrm{~nm}$. Esse método tem sido a plicado rotineiramente a un grande nümero de amostras com baixas concentrações de urânio.

HOLCOMB e YOE (1960) compararam o método proposto por FRTTZ e JOHNSOM - RTCHARD (1959), do ácido 3-(2-arsenofenilazo) - 4,5 dihidróxi - 2,7 naftalenodissulfônico trissōdico, arsenazo, com o método 
do dibenzoilmetano proposto por YOE et alii (1953). O arsenazo formava instantaneamente um complexo estável de cọ̣ azul com íon uranila, tendo absorbância máxima a $590 \mathrm{~nm}$. A relação molar entre o íon uranila e o arsenazo era de 1:1. A lei de Beer era seguida e a sensibilidade era de 0,03 ppm de urânio. Investigaram a tolexância aos diversos íons interferentes, por extração com éter. Compararam a exatidão do novo método do dibenzoilmetano: a sensibilidade do arsenazo era $50 \%$ maior que a do diben zoilmetano. O método foi aplicado para a análise de amostras sintéticas , bem como, a minérios de urânịio.

MARCZENKO (1976) descreveu métodos espectrofotométricos para determinação de urânio, usando tiocianato, dibenzoilmetano e arsena zos ... Comentou ainda, os principais interferentes, sensibilidade, bem como os intervalos de $\mathrm{pH}$ adequados para análise em cada caso.

VASCONCELLOS et alii (1980) fizeram um estudo comparativo entre alguns métodos de determinação de urânio no Instituto de Pesqui sas Energēticas e Nucleares (IPEN). Os métodos escolhidos foram anālise por ativação com neutrons epitérmicos, anālise por contagem de neutrons atrasados e anālise espectrofotométrica com dibenzoilmetano. Para o estudo dos três métodos citados, fez-se a anālise de miné rais padrões da Agência Internacional de Energia Atômica, cujo teor de urânio fora determinado por värios métodos. Os resultados obtidos para a análise de minérios padrões foram, de modo geral, concordantes entre si. 0 método com melhor precisão e exatidão foi o de contagem de neutrons re tardados, com média de $2 \%$, seguida de análise espectrofotométrica, com $3 \%$, e de anälise por ativação com neutrons epitérmicos, com precisão e 
exatidão médias em torno de $5 \%$.

2.2. Automa tização de anāiises

SKEGGS (1957) estabeleceu o conceito de análise pelo sis tema de fluxos de amostras e reagentes segmentados por bolhas de ar. A rea ção se processava na linha de fluxo até o equilíbrio dinâmico, sendo em geral, neste estágio, efetuada a medição. A partir daí, värios trabalhos foram publicados por autores isolados (THIERS, COLE e KIRSH, 1967; THIERS REED e DELANDER, 1971; BEGG, 1972), relatando as possibilidades de automa tização de métodos analîticos. Mais recentemente alguns autores (SNYDER $e$ ADLER, 1976; SNYDER et alii, STOY e CONETTA, 1976; MARGOSHES, 1977; entre outros) que passaram a constituir o chamado grupo Technicon, tem publicado trabalhos sobre o assunto. O sistema de análise foi patenteado e os equipamentos necessários para o seu procedimento atingiram preços muito elevados, impedindo o uso na maioria dos laboratórios pequenos e médios.

RUZICKA e HANSEN (1975) introduziram um novo conceito sobre automatização em Químíca Analítica, Este novo conceito baseou-se na injeção de amostras líquidas em fluído contínu• de reagentes. Desenvolveram um sistema para a determinação colorimétrica de fosfato em material de planta predigerido, a uma taxa de 120 determinações por hora. Apresentaram uma análise crítica sobre os sistemas automáticos até então : existentes.

RUZICKA e STEWART (1975) empregaram a metodologia de inje ção em fluxo contínuo na determinação de fosfato em plantas, pelo método do azul de molibdênio. Estudaram a influência dos diâmetros internos dos tubos, do comprimento de bobina de reação e do volume de amostra injetado. 
STEWART et alii (1976) utilizaram a metodologia de injeção em fluxo contínuo na determinação de nitrogênio total, em digeridos de plantas, baseada na determinação de amônia pela reação de Berthelot . Pelo uso desta técnica foi conseguida uma velocidade analítica de 110 a 180 amostras por hora, usando-se volumes das amostras tão pequenos quanto 0,3 me por anālise.

- RUZICKA et alii (1976) adaptaram, para o sistema de injeção em fluxo contínuo, a determinação de cloreto em amostras de águas pe la medida espectrofotométrica do complexo tiocianato fërrico. Estudaram os principais parâmetros que influiam no sistema. Foi conseguido, segundo os autores, uma velocidade analitica de ordem de 300 amostras por hora.

STEWART e RUZICKA (1976) desenvolvexam um método para a determinação simultânea de nitrogênio e fôsforo, em material de planta gerido. A amostra injetada sofria bifurcação, originando assim dois canais analíticos. Através dos métodós colorimētricos do indofenol azul e do fosfomolibdato, realizados independentemente em cada canal, permitia a análíse simultânea usando-se duas cubetas de fluxo e um único espectrofo tômetro. Una velocidade analítica de 200 determinações por hora foi conseguida.

HANSEN e RUZICKA (1976) descreveram a determinação de clo reto e fosfato inorgânico em soro de sangue pelo sistema de injeção em fluxo contínuo, aplicando a técnica de diälise e diluição das amostras no próprio sistema. Segundo esses autores, foi desenvolvido um microamostra dor automätico, conseguindo-se determinar cloreto e fosfato inorgânico, com boa reprodução. Conseguiu-se una velocidade analítica de 125 amostras 
por hora; volumes tão pequenos quanto $60 \mu l$ puderam ser injetados para a determinação de cloreto.

-RUZICKA e HANSEN (1977) utilizaram o sistema de injeção em fluxo contínuo em medidas potenciométricas. Usando eletrodos iônico-sele tivo, realizaram a determinação potenciomêtrica de nitrato e potássio em amostras de solo. Os sinais eram medidos com poténciômetro provido de re gistrador e a velocidade analítica foi de 125 amostras por hora com : des vio padrão de $0,8 \%$.

JØRGENSEM et alii (1977) empregaram a metodologia de inje ção em fluxo contínuo, na determinação colorimétrica de nitri to em äguas naturais, no intervalo de 0,02 a 1,00 ppm. Investigaram os efeitos do comprimento de bobina de reação sobre a velocidade analítica e sobre a sensibilidade. Observaram que a absorção referente ao branco tornava- se mais acentuada à medida que aumentava a diferença entre os indices de re fração dos padrões e do fluỉdo carregador.

KRUG et alii (1977) empregaram a metodologia de injeção em fluxo contínuo, na determinação turbidimêtrica de sulfato em äguas na turais e em material vegetal pré-digerido. Com esse método era possível alcançar a taxa de 180 determinações por hora, sendo que a reprodutibili dade e a precisão obtidas eram melhores què as obtidas pelo método: manual.

BERGAMTN et alii (1978 a) propuseram um dispositivo pa ra amortecer o pulso da injeção da amostra no sistema de fluxo. Com a a doção de tal dispositivo e de um sistema de fluxo com configuração em confluência, a sensibilidade dos métodos para determinação de ćloreto (RUZICKA et alii, 1976) e nitrato (JØRGENSEM et alii, 1977) foram melho- 
radas.

BERGAMIN et alii (1978 b) desenvolveram um dispositivo pa ra injeção de amostras, no sistema de fluxo, o qual possibilita. injetar com precisão e sem alterar o equilíbrio dinâmico do sistema, volumes de amostras no intervalo de 0,010 a 20,00 m . Com o emprêgo desse dispositi vo e de uma câmara de separação de pequena dimensão, desenvolveram um mê todo para a determinação de molibdênio por extração com solventes, alcan çando o limite de 0,05 ppm.

\section{REIS (1978) desenvolveu um método para determinação} de aluminio em extrato de solos, material vegetal predige naturais, empregando cianinạeriocromo e metodologia de injeşão em fluxo continuo. Eliminou-se a interferência do ion férrico, durante a residência de amostra no percurso analítíco, mascarando-o com ácido ascórbico ou com ácido tioglicôlico. Verificou-se os níveis de interferência do Eosfato e do fluoreto, e a partir de que níveis são significativos. Empregou-se uma solução tamponizadora, à base de acetato de amônio, para obter-se o pH desejado, antes da medida colorimétrica das amostras.

$$
\text { BERGAMIN et aliii (1978 c) descreveram uma nova configu् }
$$

ração do sistema de injeção em fluxo contínuo, onde a amostra e o reagen te são injetados, nos respectivos fluxos carregadores, no mesmo tempo. A zona da amostra e a de reagentes, confluem, com isso, havendo consumo de reagentes somente na presença da amostra. Este sistema foi denominado confluência de zonas, do ingles "merging zones". Sua eficiência foi comprovada na determinação de fosfato em material vegetal pelo método do azul de molibdênio. o consumo do ācido ascōrbico foi reduzido a $9 \%$ 
em relação ao correspondente a configuração original do sistema de injeção em fluxo contínuo.

RUZICKA e HANSEN (1978) equacionaram o efeito da dispersão da zona da amostra num sistema de análise por injeção em fluxo contínuo. Identificaram os parâmetros que permitem obter maior grau de mistura a. mostra-reagente. Estudaram a máxima velocidade entre uma amostra e outra. Fizeram uma revisão dos estudos realizados atē a data sobre os efeitos dos diferentes parâmetros na dispersão da amostra.

ZAGATTO et alii (1970a) apresentaram a utilização . do "merging zones" na determinação de cálcio, magnésio e potássio em : matè rial de plantas por espectrofotometria de absorção e emissão atômica. Fo ram estudadas as vazões dos fluxos para desenvolver um método de diluição automática das amostras com Iantânio, quando fosse necessārio. Conseguiram velocidade analítica de 300 determinações por hora, com reprodutivi dade de $0,5 \%$ e consumo de reagentes de $500 \mu \mathrm{g}$ de lantânio por determinação o qual representa $1 \%$ do comumente utilizado.

\section{RELS et alii (1972) empregaram o conceito de "merging}

zones" para aprimoramento do mētodo espectrofotométrico de alumínio . em extratos de plantas e solos, apresentado no ano anterior.

GINË et alii (1979) utilizaram o sistema de injeção em fluxo contínuo para determinação colorimétrica de manganês pelo método da formadoxima. Fluxos mascarantes dos interferentes foram estudados e ô mëtodo foi desenvolvido para amostras de águas naturais e extratos de plantas, sendo os resultados comparados com os obtidos por absorção atômi ca. Conseguiu-se sensibilidade de 0,1 ppm de manganês com boa precisão e 
velocidade analítica de 180 amostras por hora.

ZAGATTO et alii (1979b) incorporam ao sistema de injeção em fluxo contỉnuo uma unidade de dẹtilação isotérmica para amônia. Estudaram - efeito dos fluxos, alcalinidade, força iônica, pH do fluxo coletor, con centração de reagentes e volume de amostras. Este método utiliza o princí pio de "merging zones" para o reativo de Nessler, empregado na determina ção de nitrogênio total em diversos vegetais. A velocidade analítica conseguida foi de 100 amostras por hora, precisão de $3 \%$ e consumo de reagentes de $100 \mu l$ por amostra.

MEDEIROS (1979) desenvolveu um método para a determi nação de molibdênio em material de plantas pré-digerido, através da rea ção tiocianato-cloreto estanhoso, empregando-se extração com solvente no sistema de anālise química por injeção em fluxo contínuo. A velocidade analîtica foi de 60 determinações por hora e limite de sensibilidade obti do por esse método foi de 0,25 ppm. Foram estudados os efeitos da acidez, concentração dos reagentes, camaras de separação, volume de amostra, sol vente orgânicos mais adequados e os principais parâmetros que afetam as análises no sistema de fluxo contínuo. A média de recuperação, pelo teste de adição controlada é de $104 \%$ e a precisão, da ordem de $1 \%$.

GINE (.. 1979 ) desenvolveu um método analítico para determinação simultânea dos íons nitrato e nitrito em amostras de ägua e extratos de solos, por injeção em fluxo contínuo, em configuração confluente e com a utilização das zonas confluentes para economizar reagen tes. O sistema foi projetado de forma a obter uma velocidade analítica de 90 amostras por hora, com limite de sensibilidade de $0,02 \mathrm{ppm} \mathrm{N}-\mathrm{NO}_{2}^{-} \quad$ e 
consumo de 0,17 ml do reagente complexante por amostra. Foram estudados os parâmetros que afetam a redução, dispersão e complexação. Foram efetuados testes de adição controlada conseguindo-se uma recuperação média de $99 \%$ em amostras de água e solos. A precisão foi de $1,8 \%$ para nitrato na faixa de 1,0 a $5,0 \mathrm{ppm} \mathrm{N}-\mathrm{NO}_{3}^{-}$e de $0,9 \%$ para nitrito na fai xa de 0,1 a 1 ppm $\mathrm{N}^{-\mathrm{NO}_{2}^{-}}$.

BERGAMIN et alizi (1980) incorporaram no sistema de análi se por fluxo contínuo, uma coluna de troca iônica como amostradora, em determinação com ĩon amônio em àguas naturais.

ZAGATTO et alii (1980) introduziram uma nova técnica em fluxo contínuo, na determinação de nitrito em āguas . usanào fluxos in termitentes.

REIS et alizi (1980) introduziram um método que permitia selecionar pequenas porções, de uma zona de dispersão da amostra, e inje tä-la no fluxo carregador.

KRUG et aliz (1981) desenvolveram um método para determi nação espectrofotomêtrica de b.oro, em material vegetal, com azomethine-H, por injeção em fluxo contínuo.

$$
\text { ZAGATTO et alii (1981) determinaram simultaneamente, alu }
$$
minio e ferro em material vegetal digerido, empregando "merging zones" e reamos trägem.

RANGER, (1980) publicou um resumo histórico e as principais aplicações técnicas em injeção em fluxo contínuo. 
3. MATERIAL E METODOS

\subsection{Instrumentos e acessörios}

- Espectrofotômetro Vaxian, sêrie 634, equipado com cubeta de fluxo marca Hellma, tipo 178 os passo ótico : de 10min e volume $80 \mu l$.

- Registrador Radiometer, mode10 REC 61, provido de unidade de alta sensibilidade REA 112 .

- Bomba peristāltica Technicon, modelo AAII.

- Balança analítica Mettler, modelo A-30.

- Potenciómetro Radiometer, pHM 64.

- Injetor comutador, com um "loop" de amostra, construído em acrîlico.

- Tubos Solvatex, de diferentes diâmetros internos, para a bomba peristāltica.

- Tubos de polietileno de diâmetro interno 0,8mm, para a construção do módulo de anālise ("manifold").

- Vidraria e outros materiais de uso comurn em laboratório. 
3.2. Reagentes, padrões e amostras

3.2.1. Reagentes

Todos os reagentes utilizados foram pró-análise e àgua des tilada-desmineralizada foi sempre usada.

- Dibenzoilmetano

- Ācido nîtrico

- Ácido perclörico

- Ācido clorỉdxico

- Ácido fluorídrico

- Nitrato de uranila hexahidratado

- Ācido e tịleno dianino tetracêtíco (EDTA) dissodico

- Tris (hidroxinetil) aminometano

- Âlcool et ilico

As soluções foram preparadas conforme se segue:

Solução de dibenzoilmetano $0,1 \%$ v/vi foi dissolvido 1,0

grama de dibenzoilmetano em 500 m $\ell$ de álcool etỉlico. Transferiu-se para balão de $1000 \mathrm{~m} \ell$ e completou-se, lentamente e sob constante agitação, com água. Esta solução apresenta estabilidade por uma semana.

Solução de etileno diamino tetracetato dissōdico (EDTA) a

2\% m Iv: foram dissolvidos 10,0 gramas do sal dissódico em água, em um copo de $250 \mathrm{~m} l$. Transferiu-se para um balão volumétrico de $500 \mathrm{~m} \ell$ e completou-se com água e álcool etỉlico a $50 \%$ v/v.

Solução de Tris(hidroximeti1) aminometano 1 M: foram dissol vidos 60,57 gramas deste reativo em $500 \mathrm{~m} \ell$ de água. Esta solução è estável. 
Solução tampão Tris-äcido clorỉdrico: volumes convenientes (PERRII e DEMPSEY, 1974) de Tris 1M e HC1 1M foram misturados para obtenção de tampões de pH 7,0 a pH 9,0 completando-se volumes com solução hidroalcóolica a $50 \% \mathrm{v} / \mathrm{v}$.

Solução tampão acetato de sédio - äcido acético: volumes convenientes (PERRIN e DEMPSEY, 1974) de ácido acético 0,2M e acetato de sódio 0,2M foram misturados para obtenção de tampão pH 5,0, completandose volume com solução hidroạlcóolica a $50 \% \mathrm{v} / \mathrm{v}$.

\subsubsection{Padrões}

Solução padrão estoque de urânio: foram dissolvidos 2,1095 gramas de nitrato de uranila hexahidratado, $\mathrm{UO}_{2}\left(\mathrm{NO}_{3}\right)_{2} \cdot 6 \mathrm{H}_{2} \mathrm{O}$, em $100 \mathrm{ml}$ de água contendo $1 \mathrm{ml}$ de $\mathrm{HNO}_{3}$ concentrado e diluiu-se a solução com ägua, em um balão volumétrico de $1000 \mathrm{ml}$. Esta solução contém 1000 microgramas de urānio p•r $\mathrm{m} l$.

Solução padrão de uso a 100 ppm de urânio: foi preparada $\underline{\text { a }}$ travēs de diluição apropriada da solução padrão estoque.

$$
\text { Solução padrão de trabalho: a balões volumétricos de }
$$
100m1, transferiram-se 0,$25 ; 0,50 ; 1,00 ; 2,00 ; 4,00 ; 6,00 ; 8,00 ; 10,00 \mathrm{ml}$ da solução padrão de uso. Adicionou-se $0,5 \mathrm{ml}$ de solução de $\mathrm{HNO}_{3} 0,2 \mathrm{M}$ e com pletou-se o volume com solução hidroalcóolica $50 \% \mathrm{v} / \mathrm{v}$. Estas soluções se rão de concentrações: 0,$25 ; 0,50 ; 1,00 ; \ldots 10,00 \mathrm{ppm}$ de $\mathrm{U}$, apresentando pH aproximado de 3 .

Solução carregadora: foi preparada uma solução hidroalcỏoli ca a $50 \% \mathrm{v} / \mathrm{v}$, e ajustadoo $\mathrm{pH}$ a 3 pela adição de quantidade conveniente de $\mathrm{HNO}_{3}$ 


\subsubsection{Amostras}

\subsubsection{Rochas e Minérios}

Foram obtidas na Seção de Radioquímica e Química Lnalítica do CENA, provenientes da região de Caldas. Os extratos foram preparados conforme recomendação de GUEST e ZIMMERMAN (1955).

As amostras de referência, designadas por S7 e S12, foram obtidas da Agência Internacional de Energia Atômica (AIEA) e estes minérios psdrões tiveram seus teores de urânio determinados por vários métodos.

\subsubsection{Aguas naturais}

Foram obtidas na Seção de Radio ứmica e Qửnica Analítica do CENA, provenientes da bacia do Rio Piracicaba e de afluente do Rio Amazônas. As águas foram preservadas com $1 \mathrm{ml}$ de $\mathrm{HNO}_{3}$ concentrado, por litro de amostra coletada (APHA/AWWA/WPCF, 1975).

\subsubsection{Extração}

0 urânio, presente nos extratos de rochas e minérios contendo. do ferro, foi seletivamente extraído deste meio, após a adição de solução saturada de nitrato de amônio, com eter (YOE et alii, 1953;. MARCZENKO, 1976). 


\subsection{Métodos}

\subsubsection{Considerações gerais}

Os mêtodos clässicos de determinação de urânio empregam titulação volumétrica com EDTA (WELCHER, 1957) ou colorimetria com tiocianato ou peróxido de hidrogênio (YOE et ali.i, 1953). são pouco sensivais è não se adequar bem à determinação de pequenas quantidades do elemento. Frente a isto, houve necessidade de desenvolver um mêtodo que empregasse um reativo mais sensivel para o urânio.

Um estudo sistemático da reatividade de um gxande nümero de compostos orgânicos com ions inorgânicos revelou que o îon uranila produzia uma intensa e estārel cor amarela com o dibenzoilmetano. A partir desta reação, YOE et alii, publicaram em 1953, um método para determinação co lorimêtrica do urânio com dibenzoilmetano;

A maior dificuldade encontrada no método do dibenzoilmetano. era a eliminação dos interferentes e os ajustes do pH do meio. O EDTA, usa do como mascarante dos interferentes, reagia com o ion uranila em pH 3,5 a 4,0 (WELCHER, 1957). A pH inferior, a união do reativo colorimétrico e o ín em questāo era prejudicada. O melhor nível de pH era 5,3 (YOE et alii, 1953). Partindorse de soluçöes levemente àcidas, provenientes de digestões por via ümida (rochas) ou preservativos para conservação (äguas) um ajuste de pH fazia-se necessârio. Correção de acidez com hidróxido de só dio provocaya precipitação de hidróxido de uranila, $\mathrm{UO}_{2}(\mathrm{OH}) 2$; com hidróxi do de amônio, precipitava diuranato de amônio, $\left(\mathrm{NH}_{4}\right)_{2} \mathrm{U}_{2} \mathrm{O}_{j}($ IRECHER, 1957). Então,o ajuste de $\mathrm{pH}$ fez-se com tampão acetato de sódio - ācido acético, ao níve1 de 5,3 .

Para melhor deteç̧̃̃o da cor do complexo final formado, o 
pH do meio deveria ser elevado de 6,5 a 8,5. Conseguiu-se este pH, adicionando-se tampão Tris- HCl.

Posteriormente, outros métodos foram desenvolvidos, usando reativos colorimétricos como arsenazos, aluminon, glioxal, PAN, PAR,PADAP, entre outros (MARCZENKO). Dentre todos os métodos espectrofotométricos, o do dibenzoilmetano foi o mais estudado pelos diversos autores. O método de YOE et alii praticamente não foi alterado. O que se fez, foram procedimen -, tos que visavam aumento de sensibilidade, melhor eliminação de interferen tes e comparação com um novo método que se propunha.

l'endo-se em vista os fatos acirna expostos bem como, a sim plicidade, rapidez, sensibilidade e precisão do método do díbenzoilmetano, optourse por ele neste trabalho de automatização de arẩise.

3.3.2. Dibenzoilmetano e sua reação com o Ton uranita

Segundo The Merck Index, 1979, pägina 343, o dịbenzoilmetano, 1,3-difenil - 1,3 - pxopadiona, possue massa molecular 224,25, não é solūvel em águas e solubiliza-se em éter, clorofómio, âlcool etỉlico, solução hidroalcoolica contendo piridina e em álcool etílico a $57 \% \mathrm{v} / \mathrm{v}$. Apresenta-se em solução, equilïbrio tautomérico, com 96 - $98 \%$ na forma enölica, conforme a equação: 


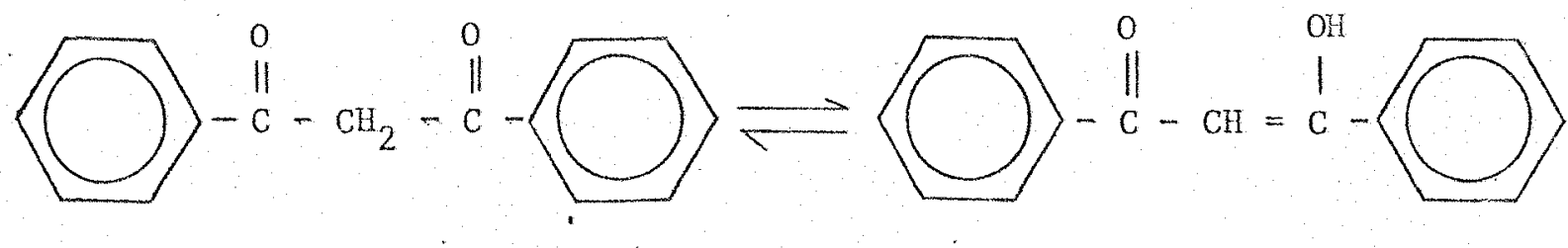

A forma enôlica do dbm e o T̃on uranila $\left(U_{2}{ }^{+2}\right)$ formam, ins tantaneamente, um quelato de cor amarela, de fórmula $U_{2} R_{2}$, cuja estrutura, sugerida por YOE et alizi (1953), é :

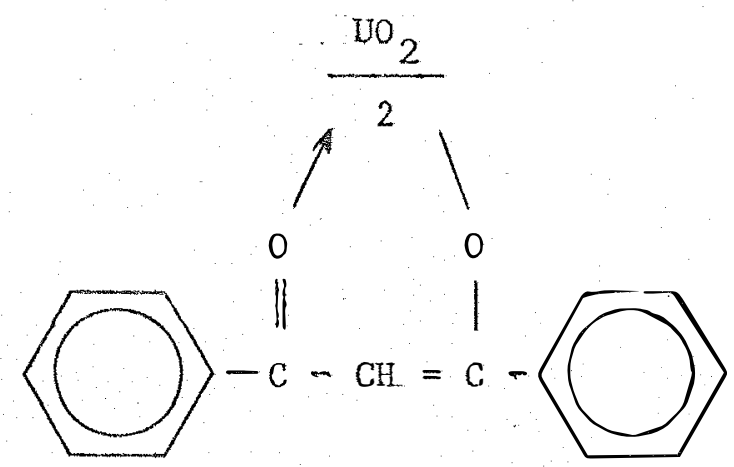


3.3.3. Método automático de anāilise por injeção em fluxo (FIA)

A anālise por injeção em fluxo (FIA) emprega um escoamento contínuo de reativos não segmentados por bolhas de ar, no interior de tubos, que vão confluindo-se no percurso analítico, onde volumes de amostras são introduzidos. Os reativos tem seu escoamento assegurado por uma bomba perïstáltica e durante o percurso analítico recebem a aliquota a ser analisada, por injeção. A espécie química, a sex detectada é formada ao mesmo tempo que é impulsionada para o detector. o sinal transiente medido, proporcional ao teor da espécie a analisar, é então registrado. Um sistema de análise, por injeção em fluxo de reativos, pode ser esquematizado num diagrama de blocos, como mostra a Figura 1.

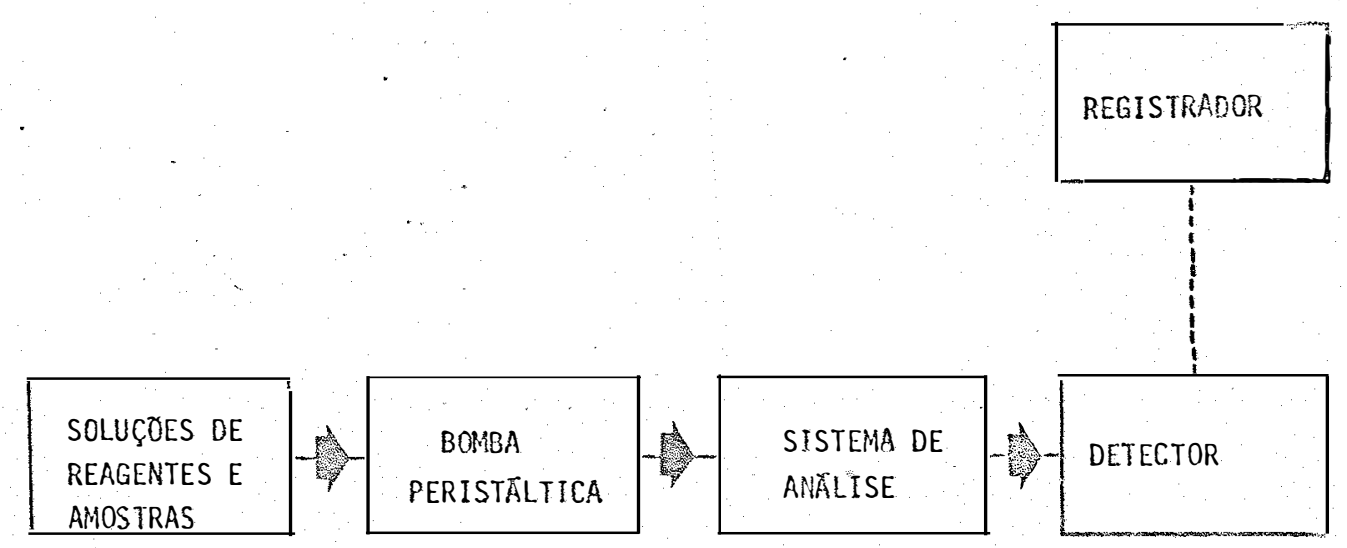

FIGURA 1. Diagrama de blocos de um sistema de análise por injeção em fluxo. 
A aplicação do princípio FIA, à anālise automātica, propicia um sistema rápido, preciso e exato, de extrama verdatibilidade e simples de ser operado (RANGER, 1980). Essa metodologia foi aplicada com sucesso em colorimetria (RUZICKA e SITWART, 1975; RUZICKA et alii, 1976; RU ZICKA e HANSEN, 1976; JØRSENSEN et alii, 1977; REIS, 1978; BERGAMIN FO et alii, 1978c; GINE et alii, 1979), em turbidimetria (KRUG et alii, 1977), espectrofotometria de absorção atômica (ZAGATTO ei alii, 1978), potenciometria (RUZICKA e HANSEN, 1977). Os mëtodos empregados, alēm da simplicidade e baixo custo, proporciónam altas taxas de determinação com baixos consumos de reagentes, sempre apresentando boa reprodutibilidade e exatidão.

o desenvolvimento desta metodologia permitiu o aparecimento de modernos dispositivos para injeção de amostras no sistema de fluxo, possibilitando injetar com precisão e sem alterar o equilíbrio dinâmico do sistema, volumes de amostras de 0,10 a $20,00 \mathrm{~m} \ell$ (BERGAMIN FO et alii, 1978 b). Este dispositivo, injetor de amostras, encontra-se esquematizado na Figura 2. 


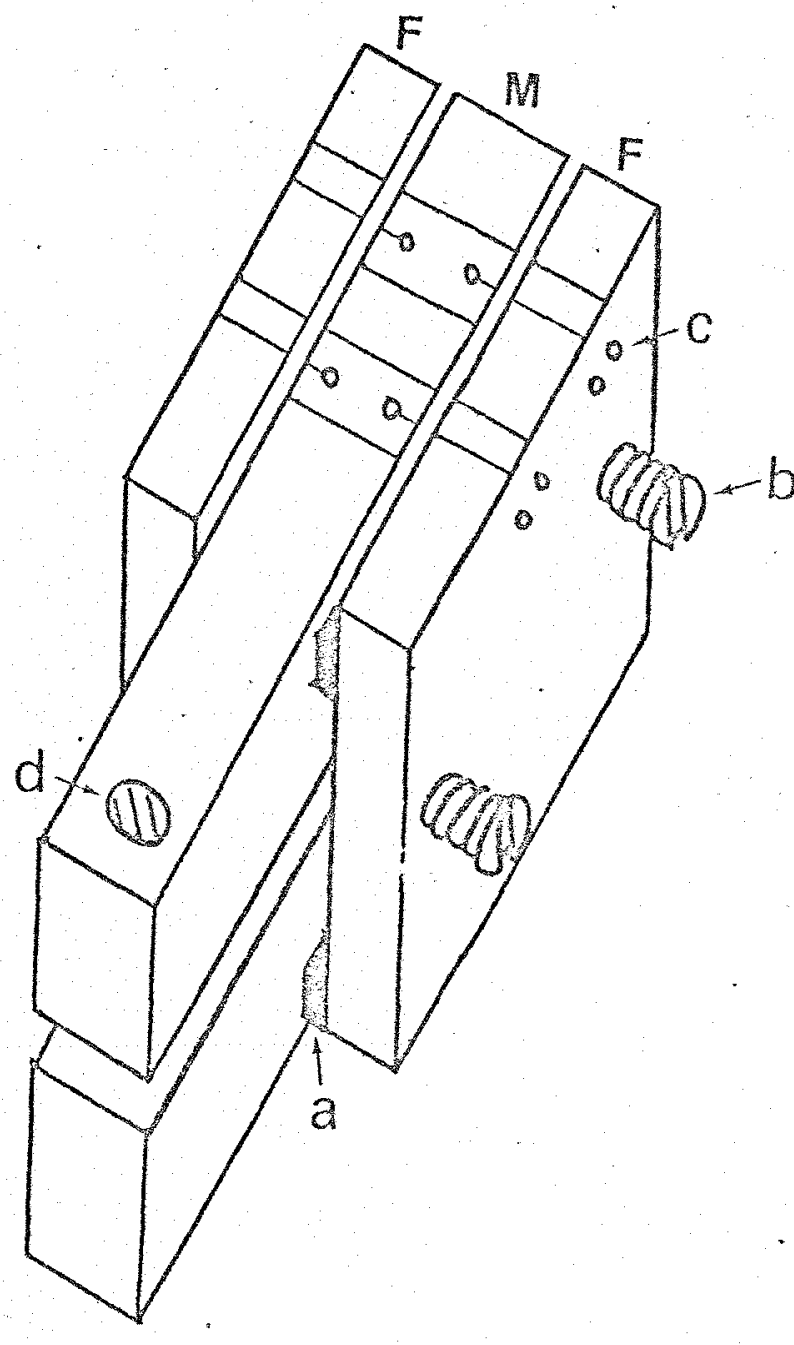

FIGURA 2. Injetor proporcional com duas secções de comutação. F e M repre sentam as placas fixa e móvel do injetor, a indica tira de borracha de si licone, $\underline{\text { G }}$ representa parafuso provido de mola, $\underline{\mathbf{c}} \overrightarrow{\mathrm{e}}$ um orifício para inser ção de tubo de polietileno constituinte do mōdulo de anālise e d é o lo cal onde se insere a alavanca pela comutação da secção móvel. 
3.3.4. Projeto do sistema de injeção em fluxo para anālise de urānio.

o projeto do sistema, para a determinação de urânio em um sistema de fluxo, baseou-se no método colorimétrico do dbm. Neste método, o urânio, na formà de ion uranila, presente em solução levemente ácida, reage instântaneamente com dbm, formando um complexo amarelo, cujo māximo de absorbância é $395 \mathrm{~mm}$ (YOE et alii, 1953). A solução do reagente orgânico foi preparada em àlcool etílico a 50\% v/v. Para evitar-se distor ção quanto a diferença entre Índices de refração entre amostras, reativos e carregadores de amostras, todos foram preparados em álcoo atílico a $50 \% \mathrm{v} / \mathrm{v}$.

0 método manual, proposto por YOE et alii, (1953), recomen dava un ajuste de pH da solução, após o tratamento com reagente colorimétrico. Como na automação as reações ocorrem em sistemas fechados, o ajuste foi feito pela adição de uma solução tamponizadora através de i. fluxo confluente. Com base experimental, foi adotado como tampão, solução de Tris (hidroximetil) amino-metano em ācido clorídrico.

Foi proposto, experimentalmente, um diagrama geral de flu xo (Figura 3.). A operação do sistema é realizada da seguinte forma: a amostra A é introduzida utilizando um injetor proporcional, sobre uma so lução carregadora $C_{A}$, impulsionada por uma bomba peristältica P. No ponto de confluência $C_{1}$, a amostra recebe a solução de EDTA, mascaradora de íons.interferenies no ponto $\mathrm{C}_{2}$ recebe a solução de dbm e no ponto $\mathrm{C}_{3}$ rece be a solução tampão. Estas soluções são igualmente impulsionadas pela bom ba perístáltica. Após passagem pela bobina de homogeneização B è passagem 


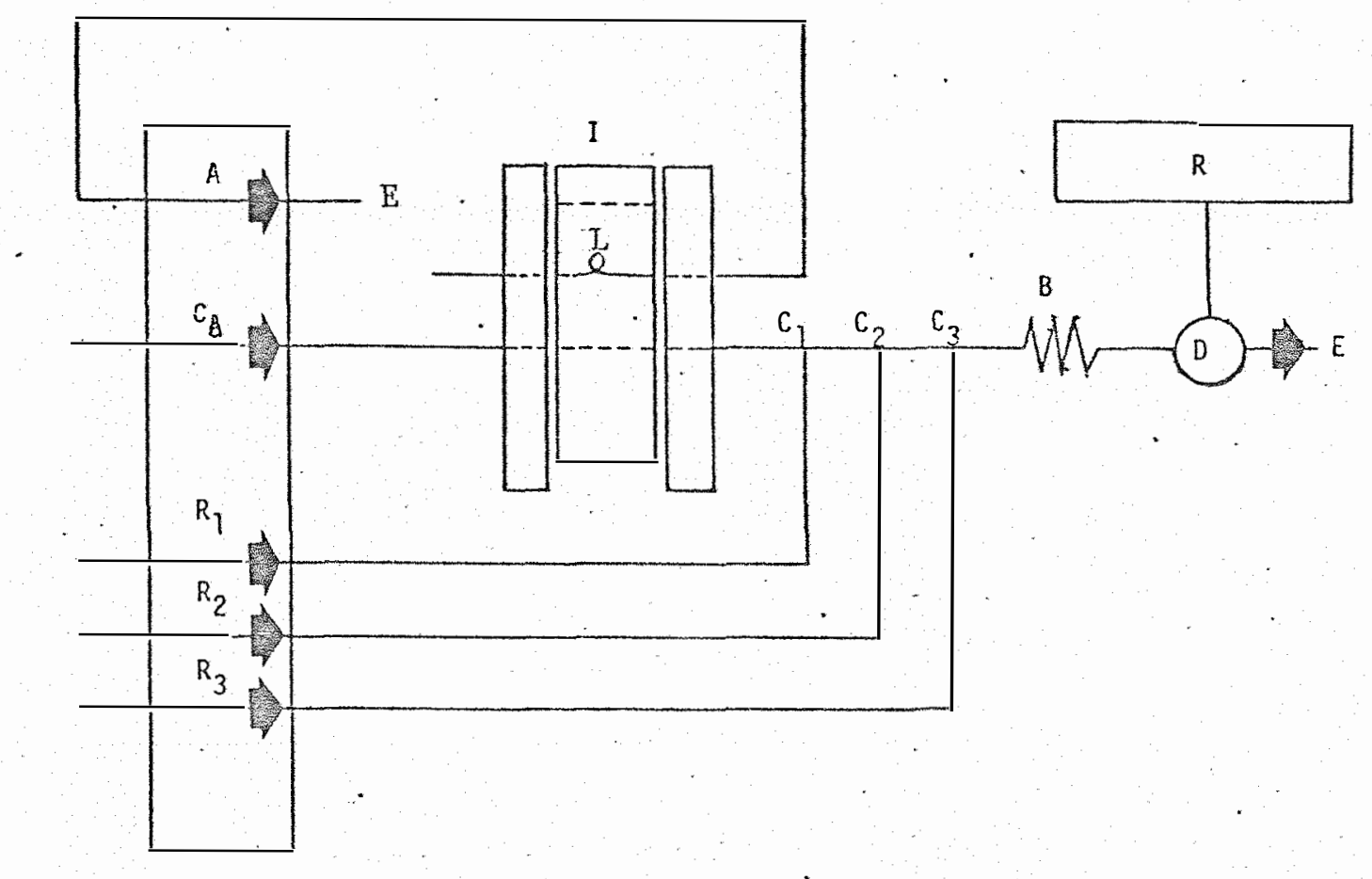

FIGURA 3. Diagrama de fluxo do sistema projetado para análise de urânio, com o injetor (I) na posição de injeção

$\mathrm{C}_{\mathrm{A}}$ solução carregadora da amostra (etanol $50 \% \mathrm{v} / \mathrm{v}$ ) fluíndo a $5,41 \mathrm{m1} \cdot \mathrm{min}^{-1}$.

A - amostra - taxa de aspiração: 2,00 ml.min ${ }^{-1}$

$\mathrm{R}_{1}$ - solução EDTA, fluíndo a $0,56 \mathrm{ml} \cdot \mathrm{min}^{-1}$

$\mathrm{R}_{2}$ - reativo colorimétrico dbm, fluíndo a $1,06 \mathrm{ml} \cdot \mathrm{min}^{-1}$

$\mathrm{R}_{3}$ - solução tampão, Tris - HCl

L - "loop" da amostra, que define o volume

$C_{1}, C_{2}$ e $C_{3}$ - representam, respectivamente, os pontos de confluência das soluçôes de EDTA, dbm e tamp̃ao, com c carregador.
B bobina de mistura
D - detector
$\mathrm{R}$ - registrador
E - descarte para o esgoto
p - bomba peristāltica 
pelo detector, a solução final é descartada para o esgoto.

Montou-se o sistema esquematizado na Figura 3. Colocaramse os reativos para serem bombeados e aguardaram-se 10 minutos para estabilização. Colocou-se o injetor na posição de aspiração e aspirou-se o branco até encher o "loop". Comutou-se, em seguida, o injetor para a posi çao de injeção. Repetiu-se a operação por três vezes. Procedeu-se, de maneira anāloga, para os demais padrões.

Inicialmente, definiu-se o comprimento de onda. Posteriormente, verificou-se os seguintes efeitos: volume de amostra injetada no sistema, concentraçao do dibenzoilmetano, acidez e ions interferentes.

\subsubsection{Definição do comprimento de onda}

Quanto ao comprimento de onda, o trabalho original de YOE et alii (1953) recomendou leituras de absorbāncia a 395nm, enquanto que BLANQUET (1957), indicou 400nm, FRANCOIS (1958) 410nm, HORTON e WHITE (1958) $416 \mathrm{~nm}$ e MAECK et alii (1959) $415 \mathrm{~nm}$.

Para definir-se melhor comprimento de onda para leitura de absorbância foram levantados espectros: a) do complexo formado, entre o Íon uranila e o dbm, contra o carregador; b) dbm contra o carregador ; c) do complexo formado contra o dbm.

\subsubsection{Efeito do volume injetado de amostras.}

Uma série de padrões, abrangendo o intervalo de 0,0 a 10,0 ppm de urânio, em solução hidroalcoólica 50\% v/v, com pH 3, foi prepara 
da. Mantendo-se constantes as concentrações dos reagentes e as respectivas intensidades de fluxos, essa série foi injetada em triplicata, numa sequência de volumes de 250, 400, 500 e $750 \mu 1$ que correspondem a "loops" de 50, 80, 100 e $150 \mathrm{~cm}$ de comprimento de tubos, respectivamente.

\subsubsection{Influēncia da concentração de dibenzoilmetano}

o trabalho original apresentado por YOE et alii (2953) reco mendou o uso de uma solução a' $1 \% \mathrm{~m} / \mathrm{v}$ de dibenzoilmetano. Outros pesquisado res recomendaram soluções que ỉam de $0,05 \%$ a $0,20 \% \mathrm{~m} / \mathrm{v}$.

Para se determinar a melhor concentraçao da solução de di benzoilmetano, foi preparada uma série de padrões, na faixa de 0,0 a $10,00 \mathrm{ppm}$ e mantendo-se constante as demais variáveis, essa série foi injetada em triplicata, variando-se a concentração de reativos, para cada sequência de padröes, de 0,005\%;0,010\%;0,050\% e 0,100\% m/v. Procurou-se trabalhar com soluções mais diluídas em fuxição de pequena solubilidade do dbm em mistura hidroalcoólica $50 \% \mathrm{v} / \mathrm{v}$.

\subsubsection{Ef eito da acidez}

O método proposto por YOE et alii (1953) e os métodos ma nuais mais recentes, afirmam que a faixa de $\mathrm{pH}$ do meio após a complexação, deveria ser 6,5 a 8,5 para uma maior sensibilidade. Como as amostras eram levemente ācidas, apōs a complexação deveriam ser lavadas, a faixa deseja da, com adição de solução concentrada de $\mathrm{NH}_{4} \mathrm{OH}$. Devido à impossibilidade 
deste procedimento do método automātico, optou-se por uma tamponização após a formação do complexo dbm-Uo ${ }_{2}^{2+}$. Foram preparados tampões tris-HC1, de $\mathrm{pH} \quad 7,0 ; 7,5 ; 8,0 ; 8,5 ; 9,0$ e mantendo-se as demais variäveis constantes, séries de padrões foram analisados.

Quatro sêries de padrões de urânio, com concentrações na fai xa de 0,0 a 10,0 ppm, foram analisadas, empregando-se o sistema preposto na figura 3. Estes padrões tinham concentrações em äcido nítrico variandode $10^{-4}$ a $10^{-2} \mathrm{M}$.

3.3.9. Efeito do comprimento da bobina de mistura

Bobina de mistura, de 50, 80,100 e $150 \mathrm{~cm}$ foram introduzidas no percurso analítico e os resultados obtidos, com uma sërie de padrões, foram analisados em conjunto.

\subsubsection{Ef eito dos Tons interferentes}

A influência dos íons interferentes foi muito bem estuda por diversos autores. YOE et alii (1953) observaram dentre 78 íons testados que $\mathrm{Fe}^{3+}, \mathrm{VO}^{2+}, \mathrm{Cu}^{2+}$ e $\mathrm{MoO}_{4}^{-}$formavam com dbm, complexos coloridos interfe rentes, BLANQUET (1957) estudou os principais mecanismos de interferencia bem como sua eliminação. Demais autores repetiram estes estudos e chegaram à conclusão que dentre os interferentes o $\mathrm{Fe}^{3+}$ era mais sério e quando a amostra contēm este íon, a separação prévia do urânio deveria ser fei ta. MARCZENKO (1976) indica que o método do dbm era empregado após o urânio ter sido extraído da amostra por um dos métodos de separação:

a) extração com solventes; b) troca iônica; e) precipitação com carbonato de sódio. Tomando-se por base a Tabela 1, que mostra a tolerância aos di- 
TABELA 1. Tolerância aos diversos îons. Concentrações mäximas permitidas dos principais fons interferếntes (extraído de YOE et alii, 1953), quan do o teor de u é de 5 ppm*

\begin{tabular}{|c|c|c|}
\hline ION & COMPOSTO UTILIZADO & $\begin{array}{c}\text { LIMITE DE CONCENTRAÇÃO } \\
(\mathrm{ppm})\end{array}$ \\
\hline $\mathrm{Al}^{3+}$ & $\mathrm{Al}\left(\mathrm{NO}_{3}\right)_{3}$ & $<1$ \\
\hline $\mathrm{Ba}^{2+}$ & $\mathrm{BaCl}_{2}$ & 10 \\
\hline $\mathrm{Ca}^{2}$ & $\mathrm{Ca} \quad\left(\mathrm{NO}_{3}\right)_{2}$ & $<1$ \\
\hline $\mathrm{Co}^{2+}$ & $\mathrm{Co}\left(\mathrm{NO}_{3}\right)_{2}$ & $<1$ \\
\hline $\mathrm{Cr}^{3+}$ & $\mathrm{Cr}\left(\mathrm{NO}_{3}\right)_{3}$ & $<1$ \\
\hline $\mathrm{Cu}^{2+}$ & $\mathrm{Cu}\left(\mathrm{NO}_{3}\right)_{2}$ & $<1$ \\
\hline $\mathrm{Fe}^{3+}$ & $\mathrm{Fe}\left(\mathrm{NO}_{3}\right)_{3}$ & $<1$ \\
\hline $\mathrm{Mg}^{2+}$ & $\mathrm{MgCl}_{2}$ & 1 \\
\hline $\mathrm{Mn}^{2+}$ & $\mathrm{MnCl}_{2}$ & $<1$ \\
\hline $\mathrm{Ni}^{2+}$ & $\mathrm{Ni}\left(\mathrm{NO}_{3}\right)_{2}$ & $<1$ \\
\hline $\mathrm{Pb}^{2+}$ & $\mathrm{Pb}\left(\mathrm{NO}_{3}\right)_{2}$ & $<1$ \\
\hline $\mathrm{Ti}^{4+}$ & $\mathrm{Ti}\left(\mathrm{SO}_{4}\right)_{2}$ & $I$ \\
\hline $2 n^{2 T}$ & $\mathrm{Zn}\left(\mathrm{NO}_{3}\right)_{2}$ & $<1$ \\
\hline
\end{tabular}

* Em 5 ppm de U, a concentração limite dos interferentes causa uma variação de 0,005 unidades de absorbância (YOE et alii, 1953). 
versos íons (YOE et alii, 1953), verificou-se, experimentalmente, a inter ferência dos mesmos sobre a sensibilidade do método proposto, para a determinação do urânio, utilizando-se o diagrama de fluxo da figura 4.

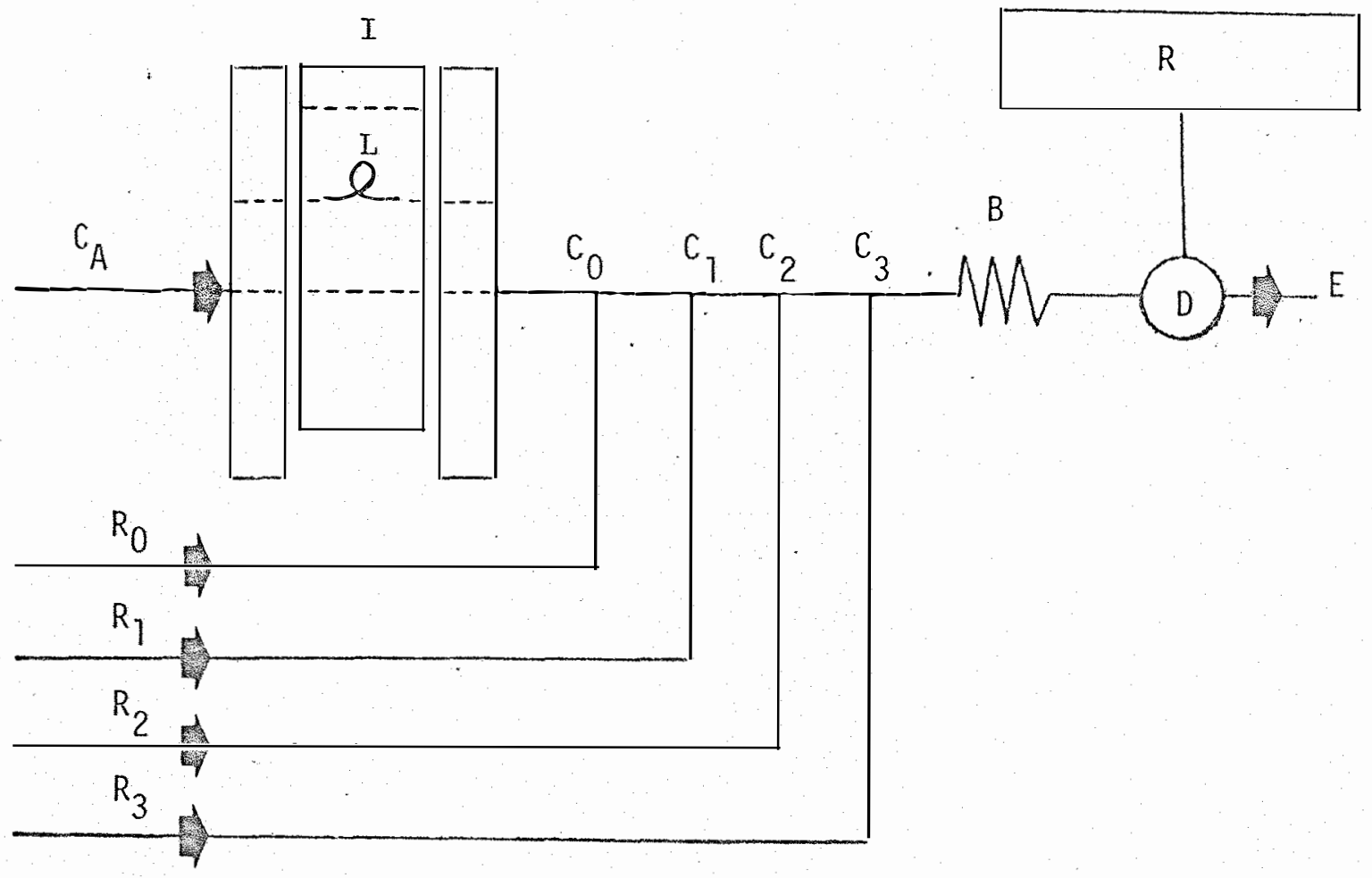

FIGURA 4. Diagrama de fluxo para estudo dos íons interferentes. Co representa o ponto de confluência da solução tampão, pH 5,0, para regular a acidez das amostras e proporcionar melhor efeito ao EDTA, cuja concentração variou de 0,$20 ; 0,50$ e $1,00 \%$. Os demais detalhes foram $j \vec{a}$ definidos na figura 3 . 
Os padrões de urânio, contendo os ĩons interferentes, foram preparados em solução hidroalcoólica, $50 \% \mathrm{v} / \mathrm{v}, 10^{-4} \mathrm{M}$ em $\mathrm{HNO}_{3}$, com concentrações dez vezes superior as concentrações máximas permitidas (YOE et alii, 1953), podendo ser vistos na Tabela 2 .

TABELA 2. Padrões de urânio, contendo os ĩons interferentes.

\begin{tabular}{|c|c|c|c|c|c|}
\hline TEOR & $\mathrm{DE}$ & URÃNIO & $(\mathrm{ppm})$ & INTERFERENTE & COMPOSTO UTILIZADO \\
\hline & & 4 & 10 & $10 \mathrm{Al}$ & $\mathrm{Al}\left(\mathrm{NO}_{3}\right)_{3}$ \\
\hline & & 4 & 10 & $100 \mathrm{Ba}$ & $\mathrm{Ba} \mathrm{Cl}_{2}$ \\
\hline & & 4 & 10 & $10 \mathrm{Ca}$ & $\mathrm{Ca}\left(\mathrm{NO}_{3}\right)_{2}$ \\
\hline & & 4 & 10 & $10 \mathrm{Co}$ & $\mathrm{Co}\left(\mathrm{NO}_{3}\right)_{2}$ \\
\hline & & 4 & 10 & $10 \mathrm{Cr}$ & $\mathrm{Cr}\left(\mathrm{NO}_{3}\right)_{3}$ \\
\hline & & 4 & 10 & $10 \mathrm{Cu}$ & $\mathrm{Cu}\left(\mathrm{NO}_{3}\right)_{2}$ \\
\hline & & 4 & 10 & $10 \mathrm{Fe}$ & $\mathrm{Fe}\left(\mathrm{NO}_{3}\right)_{3}$ \\
\hline & & 4 & 10 & $10 \mathrm{Mg}$ & $\mathrm{Mg} \mathrm{Cl}{ }_{2}$ \\
\hline & & 4 & 10 & $10 \mathrm{Mn}$ & $\mathrm{Mn} \mathrm{Cl}{ }_{2}$ \\
\hline & & 4 & 10 & $10 \mathrm{Ni}$ & $\mathrm{Ni}\left(\mathrm{NO}_{3}\right)_{2}$ \\
\hline & & 4 & 10 & $10 \mathrm{~Pb}$ & $\mathrm{~Pb} \quad\left(\mathrm{NO}_{3}\right)_{2}$ \\
\hline & & 4 & 10 & $10 \mathrm{Ti}$ & $\mathrm{Ti}\left(\mathrm{SO}_{4}\right)_{2}$ \\
\hline & & 4 & 10 & $10 \mathrm{Zn}$ & $\mathrm{Zn}\left(\mathrm{NO}_{3}\right)_{2}$ \\
\hline
\end{tabular}


Para eliminar a influência de interferentes metálicos,que tenham resistido ao processo de extração do urânio da amostra, ums solução de EDTA foi utilizada como mascarante.

\subsubsection{Caracteristicas analíticas}

\subsubsection{Exatidão}

Dois testes de exatidão foram realizados:

a) técnica da adição controlada: transferiram-se, $50 \mathrm{mi}$ crolitros de solução padrão estoque, contendo $1000 \mu g u / m \cdot l$, para balões vo lumétricos de $25 \mathrm{~m} \ell$ e os respectivos volumes foram completados com amostras, cujo teor de urânio haviam sido determinados anteriormente.

b) comparação dos resultados obtidos pelo método proposto com os teores de urânio nas amostras certificadas da Agência Internacional de Energia Atômica. As amostras designadas por S7 e S12, foram anali sadas e os resultados analíticos comparados.

Com a utilização de diagramas de fluxo da Figura 5, as a mostras preparadas conforme ítens 3.2.3.1., 3.2.3.2., 3.2.3.3., foram injetadas em triplicata no sistema.

\subsubsection{Precisão}

As amostras S7 e S12, foram analisadas, com utilização do sistema de fluxos da Figura 5, atravēs de dez injeções consecutivas sobre a solução carregadora da amostra. A precisão foi avaliada em termos do desvio padrão relativo das medidas obtidas. 


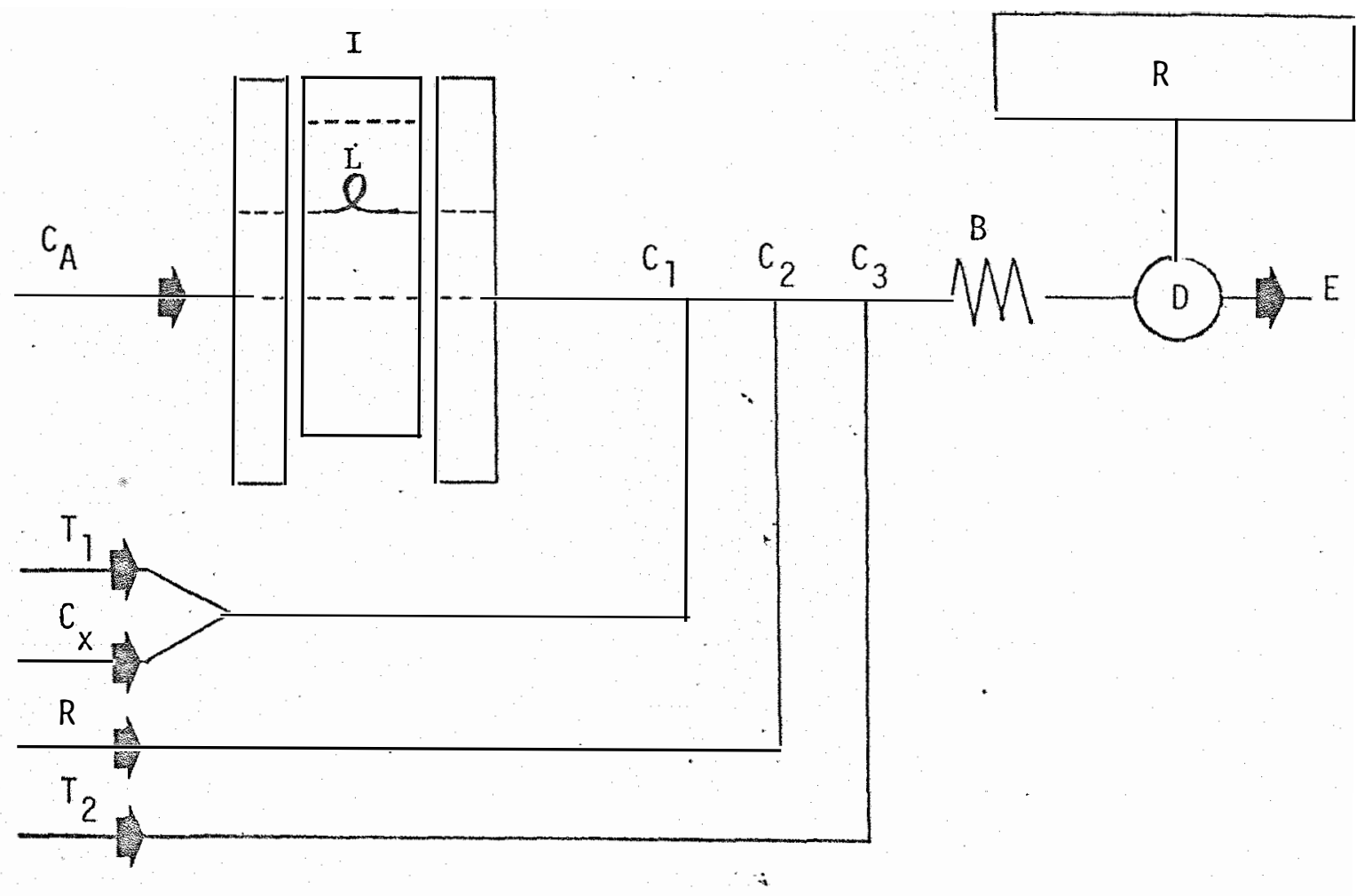

FIGURA 5. Díagrama de fluxos utilizados para a determinação de urânio em rochas e àguas naturais. $\mathrm{C}_{\mathrm{A}}$ - solução hidroalcoôlica $50 \% \mathrm{v} / \mathrm{v}$

A - amostra

$\mathrm{T}_{1}$ - Solução de acetato de sódio 0,2M - ácido acético, pH 5,0, em meio hidroalcó́lico $50 \% \mathrm{v} / \mathrm{v}$

$C_{x}$ - Solução de EDTA a $1 \%$ em meio hidroalcoölico $50 \%$ v/v .

$R$ - Solução de dibenzoilmetano a $0,1 \%$

$\mathrm{T}_{2}$ - Solução de Tris (hidroximetil) amino metano $0,05 \mathrm{M}-\mathrm{HCl}, \mathrm{pH} 8,0$

R - Registrador

$C_{1}, C_{2}, C_{3}-$ Pontos de confluência.

B - Bobina de mistura 
3.3.11.3. Velocidade analitica e consumo de reagentes

Durante a anālise de 30 amostras, mediu-se o tempo gasto e o consumo de reagentes. 


\section{RESULTADOS E DISCUSSÃO}

\subsection{Definição do comprimento de onda}

De acordo com o procedimento descrito em 3.3.5., foram levan tados os espectros de absorção, os quais são mostrados na Figura 6. A curya $A$ e o espectro de absorção do complexo dbm - $\mathrm{UO}_{2}$ contra o carregador, cuja absorção ê negligível. Nota-se que a absorção do complexo aumenta a medida em que o comprimento de onda é deslocado no sentido da região UV. Entretanto, o reativo absorve significativamente abaixo de $390 \mathrm{~nm}$ (curva $C$ L o espectro $B$ permite a avaliação do sinal analítico enquanto que a curva C fornece o valor do sinal branco. Como um compromisso, visando adequação da razão sinal/branco, optou-se, para este trabalho, pelo comprimento de onda de $400 \mathrm{~nm}$. O exame das curvas da Figura 6. mostra ainda que o valor da fenda a ser definido no espectrofotometro não é crítico e indica que outros comprimentos de onda próximos a este poderiam ser utilizados, justificando os valores de 395, 400 e 415nm empregados em outros trabalhos (YOE et alii, 1953; BLANQUET, 1957; SEIM et alii, 1959). 


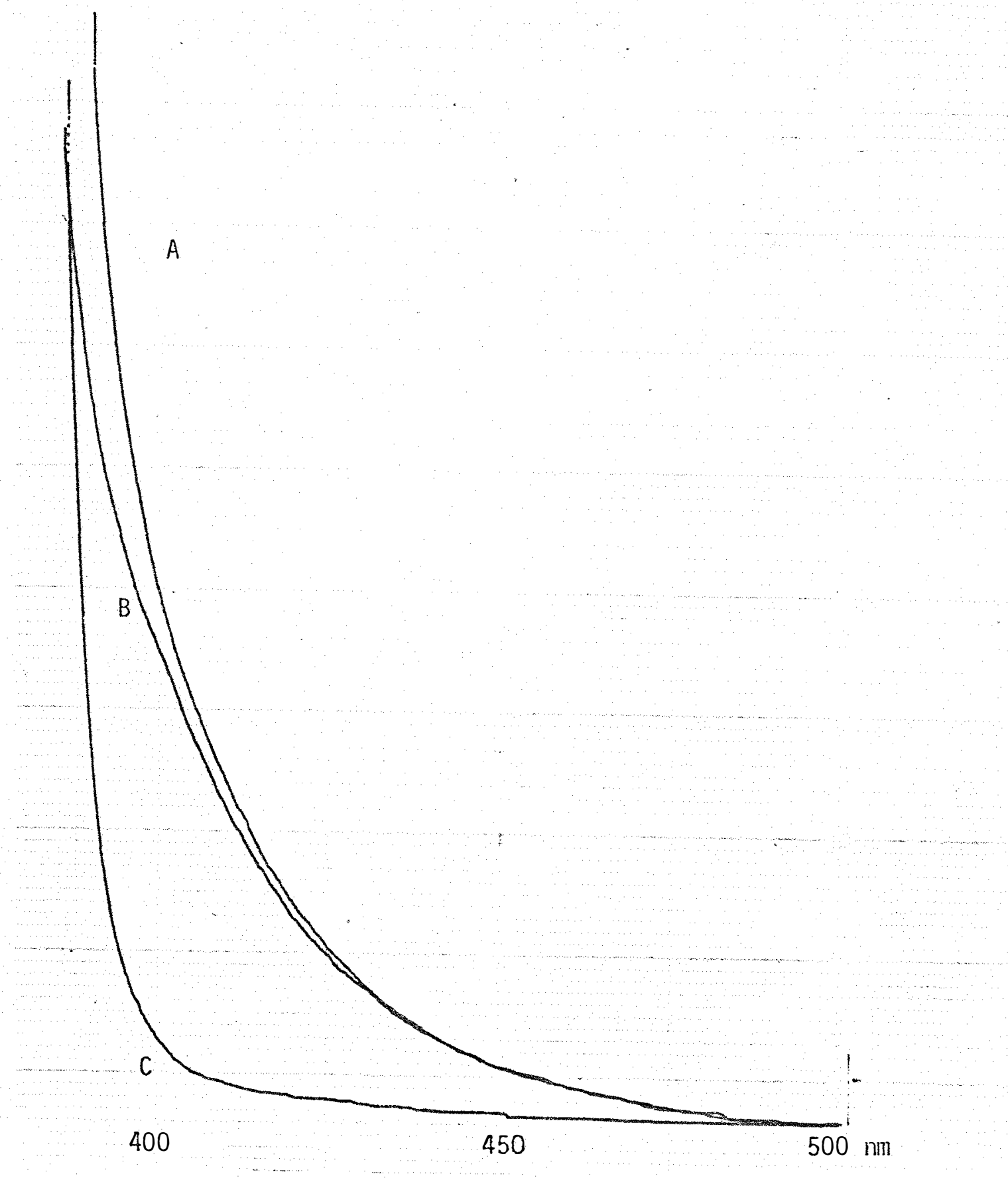

FIGURA 6. Curvas de absorção A - curva de absorção do complexo contra o carregador; B - curva de absorção do complexo contra o reagente; C - curva de absorção do reagente contra o carregador. 
4.2. Efeito do volume de amostra

De acordo com o procedimento descrito em 3.3.6., verificouse o efeito do volume de amostra injetado no sistema sobre a sensibilidade do mêtodo proposto. o resultado pode ser observado pelo exame das cur vas da Figura 7 .

0 volume foi definido em função da sensibilidade e velocidade analitica desejada. Verificou-se, experimentalmente, que quanto maior o volume injetado, maior a sensibilidade e maior o tempo de limpeza, o que comprometerâ sobre maneira a velocidade analitica. Desta forma, com a escolha de volumes de 500 ul de amostra, a velocidade analítica conseguida foi de 80 determinações por hora, com sensibilidade ao nîvel de 0,25 ppm de urânio.

Lñ aumento no volume de amostras injetado, até 500ul, proporcionou significativo aunento na absorbância. Acima de 500 $\ell$, verificouse uma tendência assintótica das curvas, para os padrōes mais baixos. 


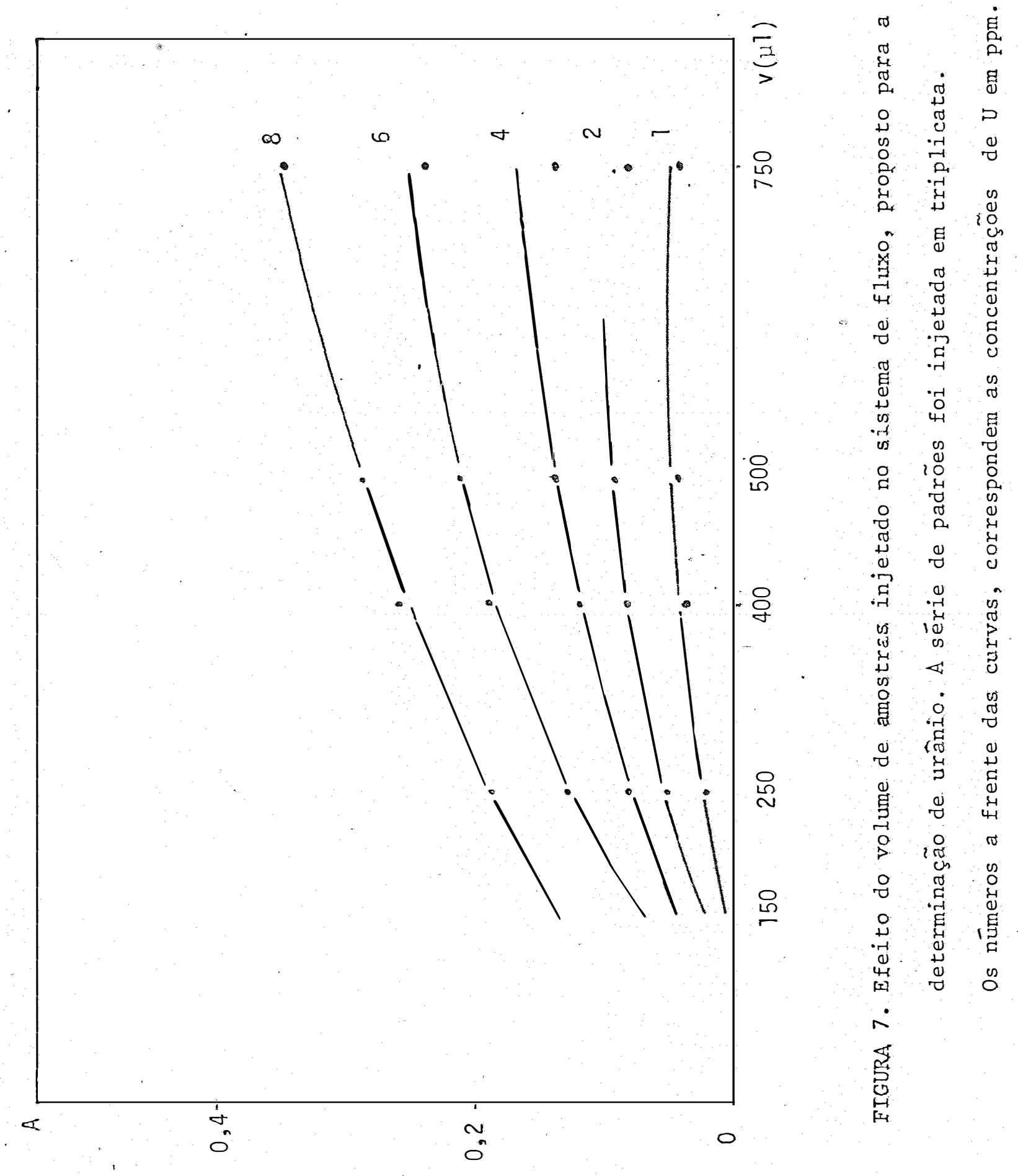


4.3. Influência da concentração de dibenzoilmetano

Conforme procedimento descrito em 3.3.7. foram obtidas curyas de padronização para diferentes concentrações de dibenzoilmetano, que podem ser observadas na Figura 8.

Verificou-se que a absorbância cresceu com o aumento da con centração de solução de dibenzoilmetano, bem como a linearidade tornou- se mais evìdente. Com concentrações acima de $0,10 \% \mathrm{~m} / \mathrm{v}$ há precipitação do rea gente, pois sua solubilidade é limitada em solução hidroalcoólica.

Considerando-se a possibilidade de precipitação e ainda o preço do reativo, optou-se por una concentração de $0,10 \% \mathrm{~m} / \mathrm{y}$ de dbm. 


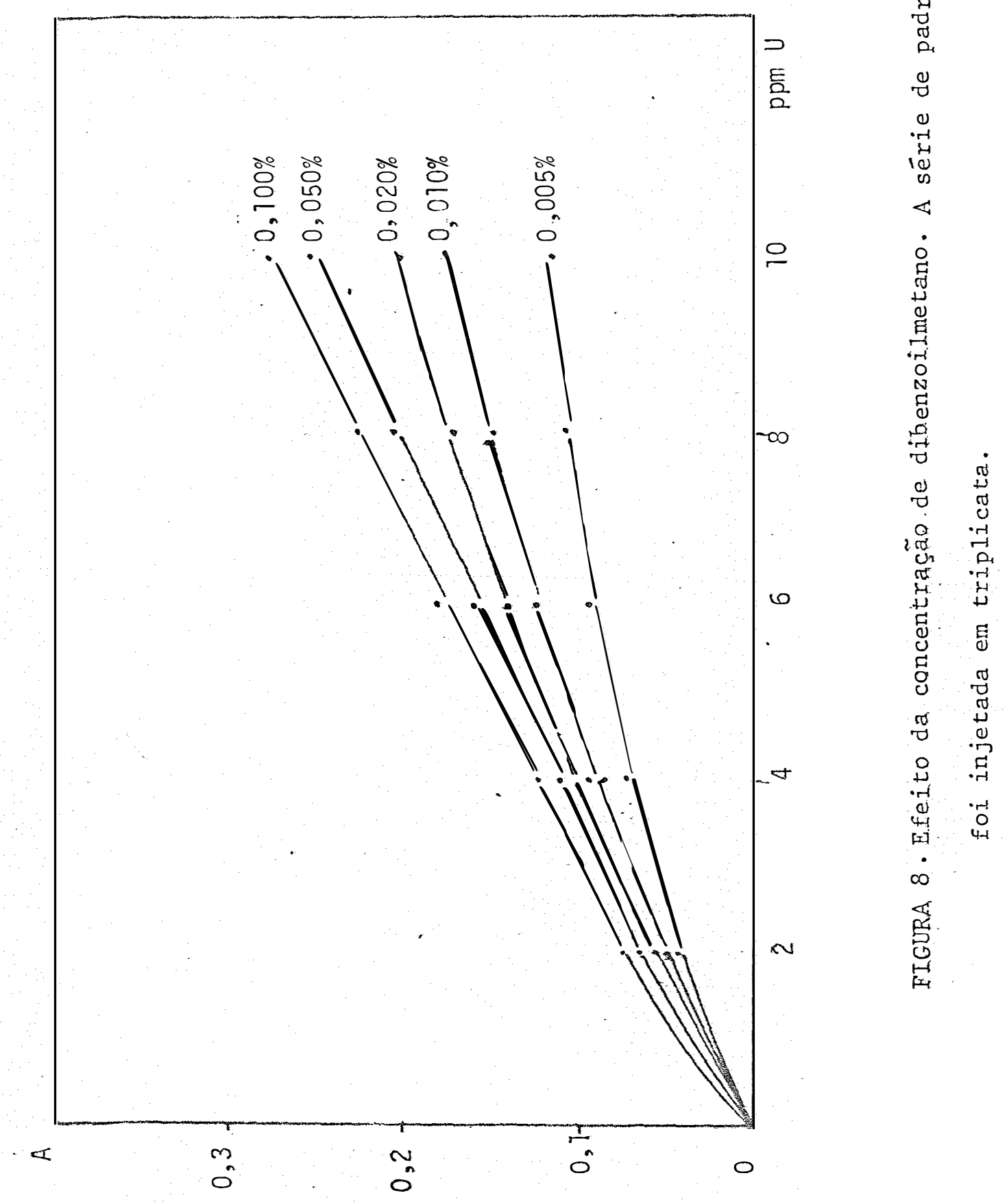


4.4. Efeito da acidez

Conforme prodecimento descrito em 3.3.8., sëries de padrões foram analisadas e, após a complexação, o pH do meio ajustado de 7,0 a 9,0, com auxílio de solução tampão Tris-HC1. Nenhum efeito foi observado, em fun ção do pI inicial das amostras na faixa de 4 a 2 , e quanto ao pH final, na faixa de solução com o complexo formado de 7,0 a 9,0 na sensibilidade do método. Por ocasião de complexação do dbm, não houve alteração sensĩvel do $\mathrm{pH}$.

4.5. Efeito do comprimento de bobina de mistura

De acordo com o descrito em 3.3.9., bobinas de mistura de $50,80,100$ e $150 \mathrm{~cm}$ foram intercaladas no percurso analitico. Os resultados podem ser observados ná Figura 9.

Da direita para a esquerda, podem ser observados os sinais de $10,8,6,4,2,1$ e 0 ppm de urânio, em quatro sêries onde variam o tamanho da bobina de mistura.

Comparando-se os sinais obtidos e os ruidos correspondentes em função de cada bobina de mistura utilizada, vexificou-se que a de $50 \mathrm{~cm}$ proporcionou o maior sinal, acompanhado de maior ruído.

Com bobinas de 80 e $100 \mathrm{~cm}$, houye uma leve diminuição do si na1, mas o ruido caiu 50\%. Entre elas, não se notou evidente alteração. Com bobina de mistura de $150 \mathrm{~cm}$, o sinal diminuiu muito pouco em relação as duas anteriores, mas o ruido caiu mais $50 \%$.

Então, visando adequação da relação sinal/ruído e conside rando-se que o aumento excessivo da bobina comprometeu a velocidade anali tica, optou-se por uma bobina de $150 \mathrm{~cm}$. Pode-se salientar que o exame da Figura 9, sugere que a reação se completa durante o tempo médio de residên cia da amostra no percurso analitico. 


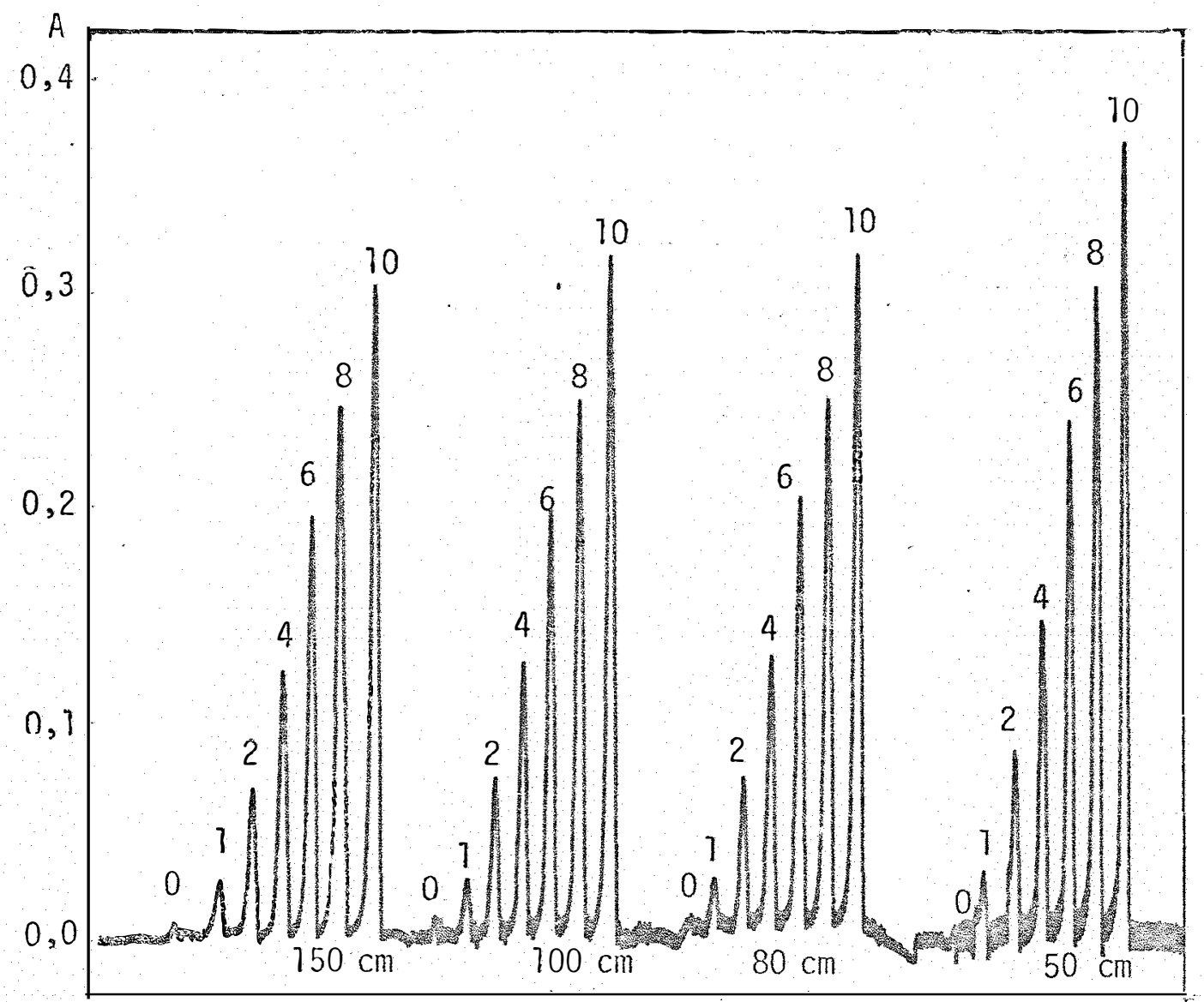

FIGURA 9. Efeito do comprimento da bobina de mistura. 
4.6. Efeito dos ions interferentes

De acordo com procedimento descrito em 3.3.10, são apresen tados na Tabela 3 os resultados obtidos do estudo das interferencias de $\mathrm{Al}, \mathrm{Ba}, \mathrm{Ca}, \mathrm{Co}, \mathrm{Cr}, \mathrm{Cu}, \mathrm{Fe}, \mathrm{Mg}, \mathrm{Mn}, \mathrm{Ni}, \mathrm{Pb}, \mathrm{Ti}$ e $\mathrm{Zn}$, sobre a determinação do urânio. A análise destes resultados mostra, que na ausência de EDTA, 음 correu interferência significativa de $\mathrm{Co}, \mathrm{Cu}, \mathrm{Fe}$ e Ni. Na presença de EDTA, estas interferências foram eliminadas, restando apenas a do Fe.

Quando a presença de ferro em maiores concentrações for inevitável, recomenda-se uma separaçao por extração de urânio (YOE et alii, 1953; FRANCOIS, 1958; MARCZE'NKO, 1976).

Os resultados obtidos foram colocados na Tabela 3.

\subsection{Caracteristicas analiticas}

\subsubsection{Exatidão}

Os testes de exatidão foram realizados de acordo com o pro cedimento descrito no ítem 3.3.11.1. Os resultados de comparação, entre o método proposto, com os teores de urânio nas amostras certificadas da Agência Internacional de Energia Atômica, podem ser observados na Tabela 4. 
Tabela 3. Performance do EDTA como mascarante.

Os dados se referem a concentrações hipotēticas obtidas a partir das medidas de soluçẽes artificiais, de concentrações conhecidas de U e dos principais interferentes, baseados na situação sem interferentes.

\begin{tabular}{|c|c|c|c|c|c|c|c|c|c|}
\hline $\begin{array}{l}\text { INTER- } \\
\text { FERENTE. }\end{array}$ & $\begin{array}{l}\text { Conc. } \\
\text { ppm }\end{array}$ & $\begin{array}{l}\text { SEM } \\
\text { EDTA }\end{array}$ & $\begin{array}{l}4 \text { ppm de } \\
\text { EDTA } \\
0,20 \%\end{array}$ & $\begin{array}{l}\text { urânio } \\
\text { EDTA } \\
0,50 \%\end{array}$ & $\begin{array}{l}\text { E DTA } \\
1,00 \%\end{array}$ & $\begin{array}{l}\text { SEM } \\
\text { EDTA }\end{array}$ & $\begin{array}{c}10 \text { ppm de } \\
\text { EDTA } \\
0,20 \%\end{array}$ & $\begin{array}{c}\text { urânio } \\
\text { EDTA } \\
0,50 \%\end{array}$ & $\begin{array}{l}\text { EDTA } \\
1,00 \%\end{array}$ \\
\hline- & - & 4,0 & 4,0 & 4,0 & 4,0 & 10,0 & 10,0 & 10,0 & 10,0 \\
\hline $\mathrm{A} 1$ & 10 & 4,2 & 4,2 & 4,0 & 4,0 & 10,8 & 10,6 & 10,0 & 10,0 \\
\hline $\mathrm{Ba}$ & 100 & 5,1 & 4,9 & 4,8 & 4,0 & 9,2 & 9,7 & 10,4 & 10,0 \\
\hline $\mathrm{Ca}$ & 10 & 4,2 & 4,1 & 4,0 & 4,0 & 9,2 & 9,4 & 9,6 & 9,8 \\
\hline Co & 10 & 16,0 & 4,0 & 4,0 & 4,0 & 40,0 & 10,8 & 10,0 & 10,0 \\
\hline $\mathrm{Cr}$ & 10 & 6,0 & 5,3 & 4,8 & 4,1 & 11,0 & 10,5 & 10,0 & 10,0 \\
\hline $\mathrm{Cu}$ & 10 & 31,0 & 4,0 & 4,0 & 4,0 & 35,0 & 10,8 & 10,0 & 10,0 \\
\hline Fe & 10 & 21,8 & 7,6 & 9,3 & 10,1 & 29,8 & 12,2 & 15,2 & 16,5 \\
\hline $\mathrm{Mg}$ & 10 & 6,6 & 9,9 & 8,0 & 5,0 & 11,6 & 21,6 & 20,0 & 12,1 \\
\hline Mn & 10 & 6,8 & 4,0 & 4,0 & 4,0 & 12,0 & 10,0 & 9,6 & 9,9 \\
\hline $\mathrm{Ni}$ & 10 & 16,2 & 4,0 & 3,6 & 4,0 & 26,0 & 10,4 & 9,6 & $9,9$. \\
\hline $\mathrm{Pb}$ & 10. & 4,4 & 4,0 & 4,0 & 4,6 & 10,0 & 9,6 & 10,0 & 10,0 \\
\hline $\mathrm{Ti}$ & 10 & 6,7 & 2,8 & 3,4 & 3,9 & 10,9 & 7,4 & 8,5 & 9,6 \\
\hline $\mathrm{Zn}$ & 10 & 4,4 & 4,0 & 4,0 & 4,0 & 10,0 & 9,1 & 10,0 & 10,0 \\
\hline
\end{tabular}


TABELA 4. Comparação dos resultados obtidos, na determinação de urânio, nas amostras certificadas da AIEA.

\begin{tabular}{|c|c|c|c|c|}
\hline \multirow{3}{*}{ AMOSTRAS } & a & b. & 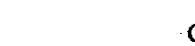 & \\
\hline & Valor aceito & Método 1 & Mētodo 2 & Desvio \\
\hline & $\% \mathrm{U}_{3} \mathrm{O}_{8}$ & $\% \mathrm{U}_{3} \mathrm{O}_{8}$ & $\% \mathrm{U}_{3} \mathrm{O}_{8}$ & $\%$ \\
\hline $\mathrm{s}_{7}$ & 0,527 & 0,799 & 0,486 & 7,78 \\
\hline$s_{12}$ & 0,014 & 0,523 & 0,022 & 36,36 \\
\hline
\end{tabular}

a média de 56 determinações independentes

b método espectrofotométrico, sem extração prévia

c método espectrofotométrico proposto, com extração prévia com éter

A determinação do teor de urânio, na amostra $S_{7}$, apresentou um esvio, no resultado, de $7,78 \% \mathrm{Na}$ amostra $\mathrm{S}_{12}$, este desyio foi de $36,36 \%$. Entretanto, esta amostra possuindo $0,014 \%$ de $\mathrm{U}_{3} \mathrm{O}_{8}$ proporcionou extrato com teor de urânio fora do intervalo de médida do método proposto. 
Os resultados do teste de recuperação, usando-se a técnica de adição controlada são apresentados na Tahela 5., revelando uma porcentade recuperação média em torno de 99,9.3\%.

TABELA 5.: Teste de recuperação com adição controlada.

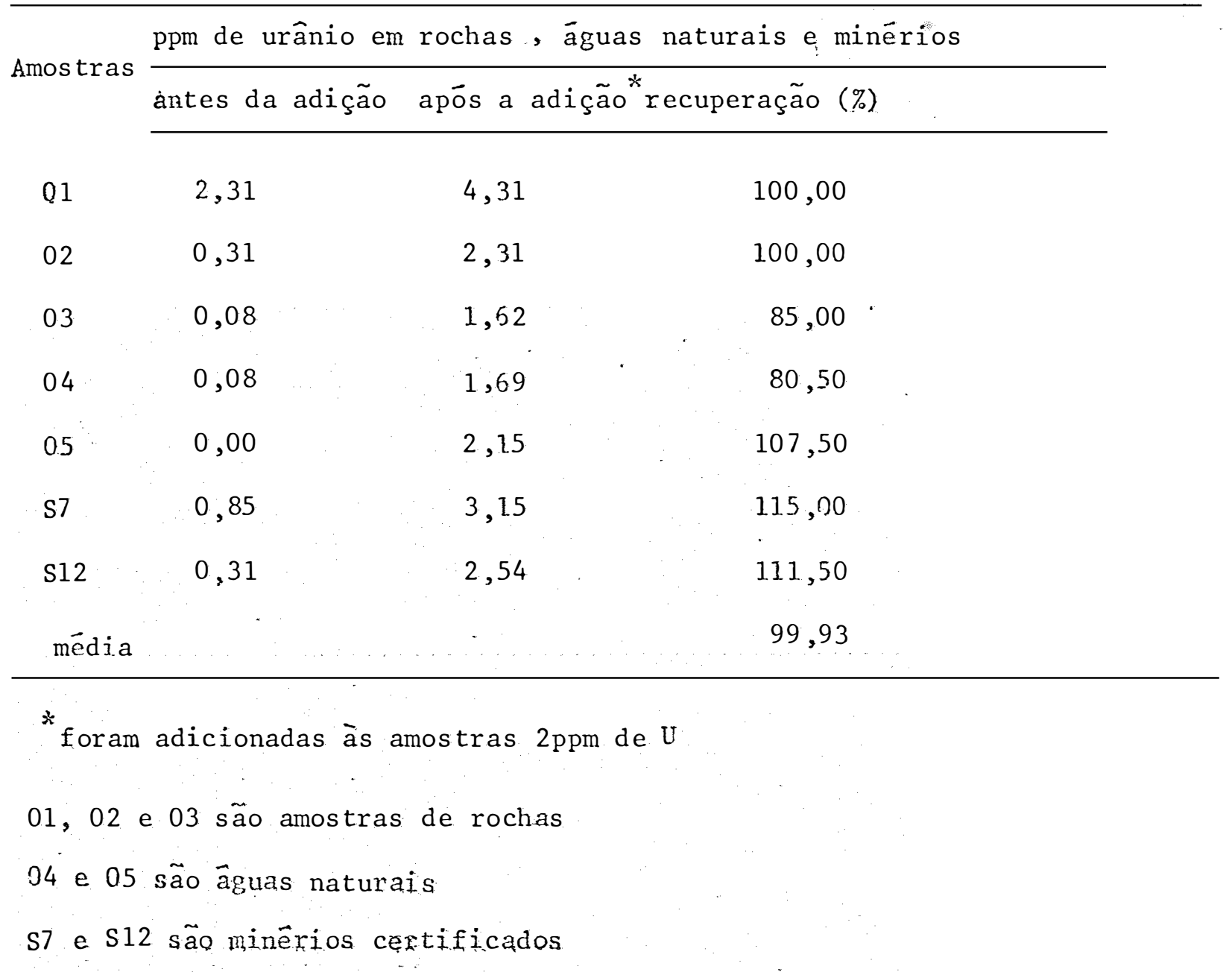




\subsubsection{Precisão}

A precisão do mêtodo proposto foi avaliado seguindo o procedimento descrito em 3.3.11.2. e apresentou um desvio padrão relativo menor que $2,08 \%$.

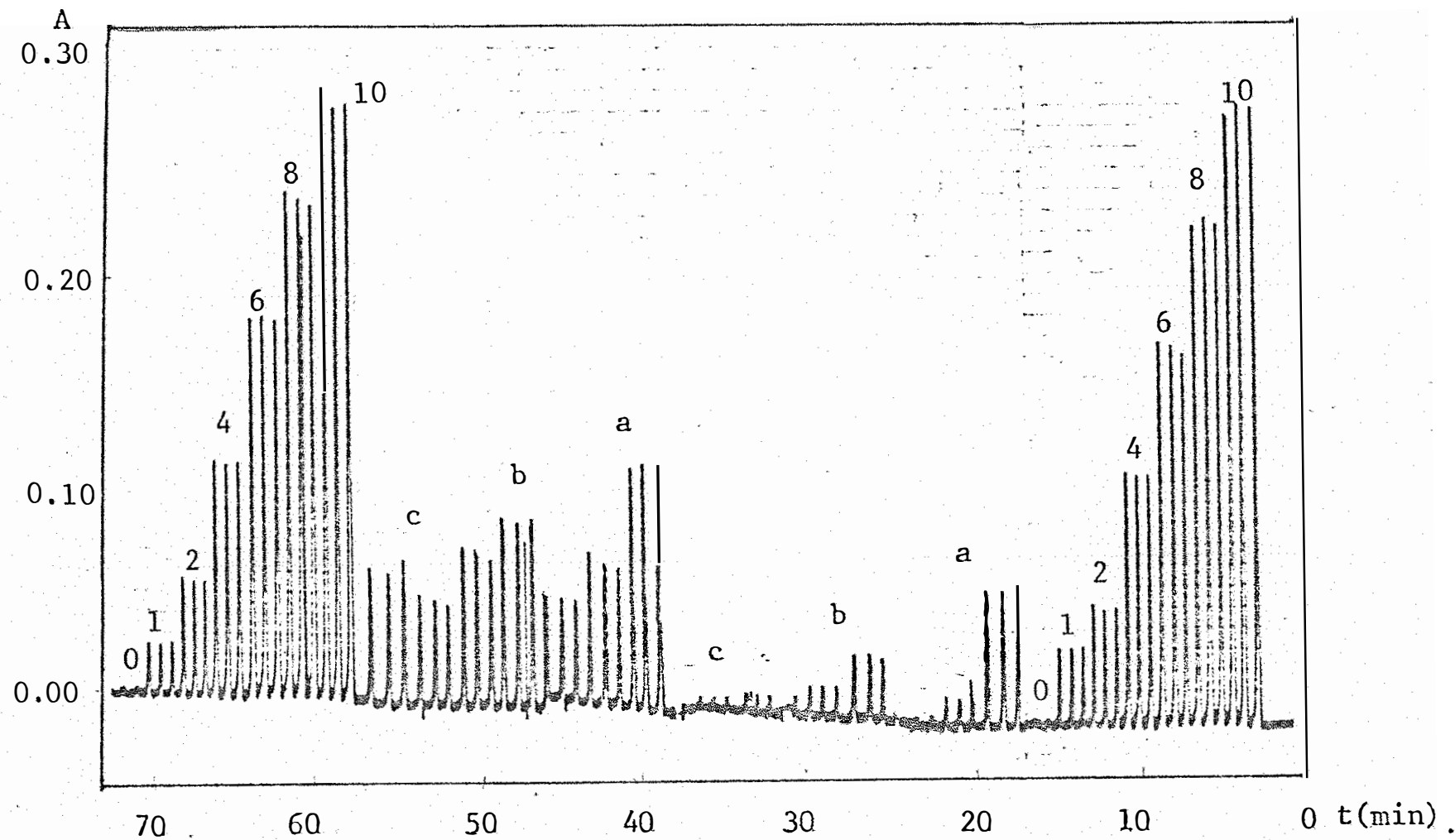

FIGURA 10. Resultado de determinação de urânio, em águas naturais e minérios, pelo método do dbm em fluxo. Da direita para a esquerda, padrões de urânio na faixa de 10,00 a a,00 ppm, amostras de rochas (a), minérios 57 e s12(b) e. äguas naturais (c), antes e após adição de 2 ppm de $U$, todas analisadas em triplicata e, novamente, a sêrie de padrões. 
4.8. Velocidade analítica e consumo de reagentes.

A velocidade analítica do método proposto pode ser observado na Figura 10, girando em torno de 80 determinações por hora, na faixade $1 \mathrm{ppm}$ a $10 \mathrm{ppm}$ de urânio. Esta velocidade poderá ser aumentada desde que não comprometa a sensibilidade do método, levando-se ẹ consideração as argu mentações apresentadas no îtem 4.2 .

Na anâlise das amostras foram gastos:

Carregador $\ldots \ldots \ldots \ldots \ldots \ldots \ldots \ldots \ldots \ldots \ldots \ldots \ldots \ldots \ldots \ldots \ldots \ldots, 324,60 \mathrm{~m} 1 / \mathrm{hora}$

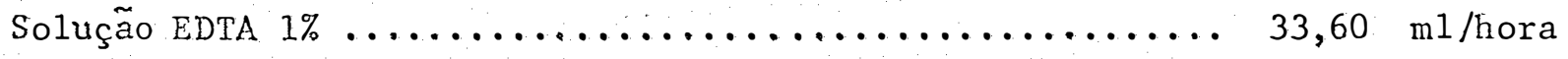

Solução dbm $0,1 \% \ldots \ldots \ldots \ldots \ldots \ldots \ldots \ldots \ldots \ldots \ldots \ldots \ldots \ldots, 63,60 \quad \mathrm{ml} / \mathrm{hora}$

Solução tampão acetato de sôdio $0,2 \mathrm{M} \ldots \ldots \ldots \ldots \ldots \ldots \ldots . \ldots 33,60 \mathrm{~m} 1 / \mathrm{h}$

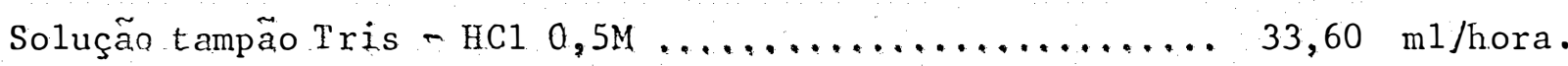


5. CONCLUSOES

o elemento urânio pode ser determinado espectrofotométrica mente em rochas, minërios e águas naturais, pelo método do dibenzoilmeta no, empregando-se análise de injeção em fluxo. As amostras, preparadas em solução hidroalcoólica a $50 \% \mathrm{v} / \mathrm{v}$, permitiu, após separação dos interfe'rentes, ganho de tempo com análise de rotina, resultando uma velocidade analítica de 80 determinações por hora.

- As absorbâncias devem ser medidas de 400 a $420 \mathrm{~nm}$. Abaixo de $400 \mathrm{~nm}$, o reativo passa a absorver. cada vez mais intensamente. Acima de $420 \mathrm{~nm}$, a sensibilidade diminui bastante. Estes resultados obtidos estão de acordo com os dados apresentados na literatura.

Volumes de amostras injetadas com "loop" de $150 \mathrm{~cm}(750 \mu 1)$ propiciam uma melhor sensibilidade. Um aumento no volume injetado acarretou aumento no tempo morto para deteç̧ão.

A sensibilidade aumentou com a elevação de concentração do dibenzoilmetano. Abaixo de $0,05 \% \mathrm{~m} / \mathrm{v}$ em dibenzoilmetano, a partir de $6 \mathrm{ppm}$ de urânio, a curva ganhou tendência assintótica. Acima de 0,05\% m/v, observou-se linearidade das curvas.

Trabalhando-se com soluções hidroalcoölicas a $50 \% \mathrm{v} / \mathrm{v}$, conseguxu-se soluções de dibenzoilmetano a $0,1 \%$. Com volumes inferiores de 
àlcool, a solução era instáve1, chegando a ocorrer precipitação do reagen te antes do termino do preparo de sua solução.

As amostras podem ter $\mathrm{pH}$ variando de 2 a 4 antes da reação com o dibenzoilmetano, sem alterar a sensibilidade e reprodutibilidade do método. Por outro lado, uma elevação do $\mathrm{pH}$, favoreceu a ação quelan . te do EDTA.

$0 \mathrm{pH}$ final do meio, antes de se efetuarem leituras de absorbância, foi tamponizado com uma solução de Tris (hidroximetil) aminome tano-äcido clorídrico. Não se observou variação na sensibilidade, na faixa de $\mathrm{pH} 7$ a 9 .

A bobina demistura adotada, para melhor eficiência do sis tema, foi de $150 \mathrm{~cm}$. Abaixo, a homogeneização não era perfeita, causando muito ruído na linha de base. Acima, a sensibilidade dininui e o tempo morto aumenta.

0.EDTA, 1,00\% m/v, eomo mascarante do Fe (III), mostrouse eficiente até a concentraçãode $1 \mathrm{ppm}$ do elemento nas amostras. Para con centrações superiores, recomenda-se uma separação prévia por extração com solventes.

o método proposto, para anālise do uränio, em rochas, minērios e āguas naturais apresenta limite de sensibilidade em torno de $0,25 \mathrm{ppm}$. Uma amostra típica ( $4,0 \mathrm{ppm}$ de urânio no extrato) pode ser determinada com precisão de $97,92 \%$.

A velocidade de medida conseguida, empregando-se o método proposto, foi de 80 determinações por hora, com um consumo de 242 , $70 \mathrm{~m} 1$ de álcool etílico, $0,159 \mathrm{~g}$ de EDTA, $0,0363 \mathrm{~g}$ de dibenzoilmetano e 2,4228g de Tris (hidroximeti1) aminometano. 


\section{LITERATURA}

ADANS, J.A.S. e W.J. MAECK, 1954. Fluorometric and colorimetric microdetermination of uranium in rocks and minerals. Anal. Chem., Washington, 26 (10): $1635-1639$.

BERGAMIN FO, H.; B.F. REIS e E.A.G. ZAGATTO, 1978a. A new device for improving sensitivity and stabilization in flow-injection analysis. Ana1. Chim. Acta, Amsterdam, 97:427-431.

BERGAMTN FO, H.; J.X. MEDEIROS; B.F. REIS e E.A.G. ZAGATTO, 1978b. Solvent extraction in continuous flow injection analysis. Determination of molibdenum in plant material. Ara1. Chim. Acta, Amsterdam, 101:9-16.

BERGAMIN FO, H.; E.A.G. ZAGATTO; B.F. REIS e F.J. KRUG, 1978C. Merging zones in flow injection analysis. Paxt 1. Double proportional injector and reagent consumption. Anal. Chim. Acta, Ams terdam, 101:17-23.

BERGAMIN FO, H.; B.F. REIS, A.O. JACINTHO E E.A.G. ZAGATTO, 1980. Ion exchange in flow injection analysis. Determination of ammonium ions at the $\mu \mathrm{g}^{-1}$ leve1 in natural waters with pulsed Nessler reagent. Ana1. Chim. Acta, Ams terdam, 117;81-89.

BLANQUET, P., 1957. Dosage colorimétrique de i'uranium par le dibenzoylme thane. Ana1. Chim. Acta., Amsterdam, 16:44-56.

CHENG, K.L., 1958. Determination of traces of uranium with 1-(2pyridylazo) 2 - naphto1. Ana1. Chem., Washington, 30(6):1027-1030. 
FRANCOIS, C.A., 1958. Rapid spectrophotometric determination of submilligram quantities of uranium. Anal. Chem., Washington, 30(1):50-54.

GINÉ, M.F.; E.A.G. ZAGATTO e H. BERGAMIN FO, 1979. Semiautomatic determimination of manganese in natural waters and plant digest by flow in jection analysis. Analyst, London, 102:714-722.

GINÉ, M.F.j 1979. Determinação espectrofotométrica simultânea de nitrato e nitrito em äguas e solos por injeção em fluxo contínuo. Piracicaba, ESALQ/USP, 70p. (Dissertação de Mestrado)

GUEST, R.J. e J.B. ZIMMERMAN, 1955. Determination of uranium in uranium concentrates. Use of ethyl acetate. Anal.Chem. Washington, $27(6): 931-936$

HANSEN; E.H. e J. RUZICKA, 1976. Flow injection analysis. Part VI. The de. termination of phosphate and chloride in blood serum by dialysis and sample dilution. Anal. Chim. Acta, Amsterdam, 87:353-363.

HOLCOMB , H.P. e J.H. YOE. 1960. Spectrophotometric determination of uranium with 3-(2-arsonophenylazo)-4,5-dihydroxy-2,7-naphthalenedisulfonic acid (trisodium sait). Ana]. Chem., Washington, 32 (6):612-617.

HORTON, A.C. e J.C.WHITE, 1958. Separation of uranium by solvent extraction with tri-n-octylphosphine oxide. Direct calorimetric determination with dibenzoylmethane. Anal. Chem. Washington, 30(11):1779-1784.

JØRGENSEN, S.S.; H. BERGAMIN FO; E.A.G. ZAGATTO; F.J.KRUG e S.R.B. BRINGEI, 1977. Determinação de nitrato em águas naturais através do sistema de. injeção em fluxo contínuo. Piracicaba, CENA 28p. (Boletim Científico no 047). 
KRUG, F.J.; H. BERGAMIN FO; E.A.G. ZAGATTO e S.S. JØRGENSEN, 1977. Rapid determination of sulphate in natural waters and plant digest by conti nuous flow injection turbidimetry. Analyst, London, 102:503-508.

KRUG, F.J.; J.MORTATTI; L.C.R. PESSENDA; E.A.G. ZAGATTO e H. BERGAMTN FO, 1981. Flow injection spectrophotometric determination of boron in plant material with azomethine H Ana1. Chim. Acta, Amsterdam, 125:29-35.

MAECK, J.W.; G.L. BOOMAN; M.C. ELLIOTT e J.E. REIN, 1959. Spectrophotometric extration methods specific for uranium. Anal. Chem., Washington, $\underline{31}(7): 1130-1134$

MARCZENKO, 2.; 1976. Espectrophotometric Determination of Elements. New York. John Wiley, p. 574-585.

MEDEIROS, J.X., 1979. Determinação de molibdênio em material de plantas por extração com solventes em fluxo contínuo. Piracicaba, ESALQ/USP, 100p. (dissertação de mestrado).

POLLARD, F.H.; P. HANSON e W.J. GEARY, 1959. 4-(2-pyridylazo) - resorcinol as a possible analytical reagent for the colorimetric estimation of cobalt, lead and uranium. Ana1. Chim. Acta, Ams terdam, 20:31-37.

PERRTN, D.D. e B. DEMPSEY, 1974. Buffers for $\mathrm{pH}$ and metal ion control. London. Chapman and Ha11, p. 143

RANGER, C.; 1980. Flow injection analysis. Principles techniques applications design. Anal. Chem., Washington, 53 (1):20A-32A.

REIS, B.F.; 1978. Determinação colorimétrica de alumínio em águas, plantas e solos por injeção em fluxo contínuo. Piracicaba, ESALQ/USP: p.64.(Dis 
sertação de Mestrado).

REIS, B.F.; H. BERGAMIN FO, E.A.G. ZAGATTO e F.J. KRUG, 1979. Merging zones in flow injection analysis. Part 3. Spectrophotometric determination of alumminium in plant and soil materials with sequential addition of pulsed reagents. Anal. Chem. Acta, Amsterdam, 107:309-317

REIS, B.F.; E.A.G. ZAGATTO, A.O. JACINTHO, F.J. KRUG e H. BERGAMIN FO, 1980. Merging zones in flow injection analysis. Part.4. Simultaneous spectrophotometric determination of total nitrogen and phosphorous in plant material. Ana1. Chim. Acta, Amsterdam, 119:305-311.

RUZICKA, J. e E.H.HANSEN, 1975. Flow injection analysis. Part I. A new concept of fast continuous flow analysis. Anal. Chim. Acta, Amsterdam, 78: 145-157. RUZICKA, J. e E.H. HANSEN, 1977. Flow injection analysis. Part VII. Use of ion-selective electrode for rapid analysis of soil extracts and blood serum. Determination of potassium, sodium and nitrate and nitrite. Anal. Chim. Acta, Amesterdam, 88:1-16.

RUZICKA, J. e E.H. HANSEN, 1978. Flow injection analysis. Part X. Theory, techniques and trends. Anal. Chim. Acta, Amsterdam, 99:37.

RUZICKA, J. e J.W.B. SIEWART, 1975. Flow injection analysis. Part II. U1tra fast determination of phosphorous in plant material by continuous flow spectrophotometry. Ana1. Chim. Acta., Amsterdam, 79:79-81.

RUZICKA, J. ; J.W.B. STEWART e E.A.G. ZAGATTO, 1976. Flow injection analysis. Part IV. Stream sample splitting and its application to the continuous spectrophotometric determination of chloride in brackish waters. Anal.Chim. Acta, Amsterdam, 81:387. 
SANDELL, E.B., 1959. Colorimetric determination of traces metals. 3. ed. New York, Interscience Publischers, 1032p.

SEIM, H.J.; R.J. MORRIS e R. G. PASTORINO, 1959. Application of ion exchan ge to the colorimetric determination of traces amounts of uranium using dibenzoylmethane, Ana1. Chem., Washington, 31 (5): 957-958.

SKEGGS, L.T. 1957. An automatic method for colorimetric analysis.

Amer. J. Clin. Pathol. Ohio, 28:311-322.

SKINNER, B.J.; 1970. Recursos Minerais da Terra, São Paulo. Edgard Bllicher Ltda., p. 113-117.

SIEWART, J. W. B. e J. RUZICKA, 1976. Flow injection analysis. Part V. Simul taneous determination of nitrogen and phosphorous in acids digests of plant material using a single spectrophotometer. Anal. Chim. Acta. Amsterdan, $82: 137-144$.

SIEWART; J.W.B.; J. RUZICKA; H. BERGAMIN FO e E.A.G. ZAGATTO, 1976. Flow injection analysis. Part III. Comparison of continuous flow espectropho tometry and potentiometry for the rapid determination of the total ni trogen content in plant digest. Anal. Chim. Acta., Amsterdam, 81:371-386.

TACEER, L.L. e F.: BARKER, 1957. Determination of uranium in natural waters. Ana1. Chem., Washington, 29(11):1575-1578.

VASCONCELLOS, M.B.A.; M.J.A. ARMELIN; R. FULFARO e F.W. LIMA, 1980. A comparative study of some methods for the determination of uranium used at. the Instituto de Pesquisas Energéticas e Nucleares. São Paulo, Instituto de Pesquisas Energēticas e Nucleares. 17p. (IPEN-PUB-17). 
WELCHER, F. J., 1957. The analytical uses of ethylenediamine tetracetic acid.New Jersey, D. Van Nostrand, p. 253-321.

YOE, J.H.; W. FRITZ e R.A. BLACK, 1953. Colorimetric determination of ura nium with dibenzoylmethane. Anal. Chem., Washington, 25(8):1200-1204.

ZAGATTO, E.A.G.; F.J. KRUG; H. BERGAMIN FO; S.S. JØRSENSEN e B.F. REIS , 1979a. Merging-zones in flow injection analysis. Part 2. Determination of calcium, magnesium and potassium in plant material by continous flow injection atomic absorption and flame enmission espectrometry. Anal. Chim. Acta, Ams terdam, 104:279-289.

ZAGATTO, E.A.G. ; B.F. REIS; H. BERGAMIN FO e F.J. KRUG, 1979b. Isothermal distillation in flow injection analysis. Determiantion of total nitro gen in plant material. Anal. Chim. Acta., Amsterdam, 109:45-54.

ZAGATTO, E.A.G.; A.O. JACINTHO; J. MORTATTI e H. BERGAMIN FO, 1980. An impro ved flow injection determination of nitrite in waters by using intermit tent flows. Anal. Chim. Acta, Amsterdam, 120:399-403.

ZAGATTO, E.A.G.; A.O. JACINTHO; L.C.R. PESSENDA; F.J. KRUG; B.F. REIS e H. BERGAMIN FO, 1981. Merging zones in flow injection analysis. Part 5. simultaneous determination of aluminium and iron in plant digest by a zone-sampling approach. Anal. Chim. Acta, Ams terdam, 125:37-43. 